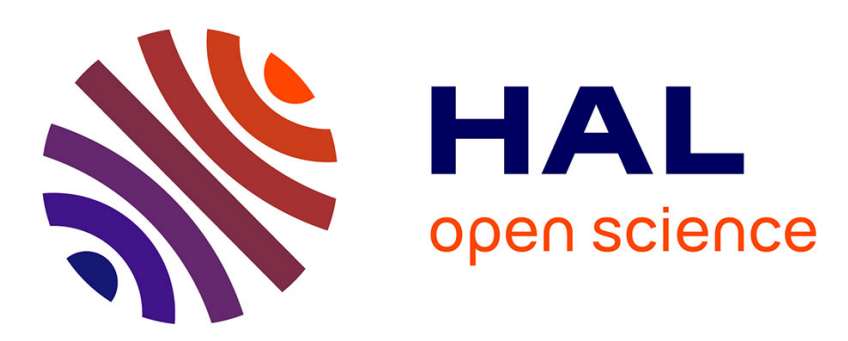

\title{
SHS in Ni/Al Nanofoils: A Review of Experiments and Molecular Dynamics Simulations
}

Florence Baras, Vladyslav Turlo, Olivier Politano, Sergey Georgievich Vadchenko, Alexander Sergeevich Rogachev, Alexander Sergeevich Mukasyan

\section{- To cite this version:}

Florence Baras, Vladyslav Turlo, Olivier Politano, Sergey Georgievich Vadchenko, Alexander Sergeevich Rogachev, et al.. SHS in Ni/Al Nanofoils: A Review of Experiments and Molecular Dynamics Simulations. Advanced Engineering Materials, 2018, 20 (8), pp.1800091. 10.1002/adem.201800091 . hal-02344600

\section{HAL Id: hal-02344600 \\ https://hal.science/hal-02344600}

Submitted on 19 Jan 2022

HAL is a multi-disciplinary open access archive for the deposit and dissemination of scientific research documents, whether they are published or not. The documents may come from teaching and research institutions in France or abroad, or from public or private research centers.
L'archive ouverte pluridisciplinaire HAL, est destinée au dépôt et à la diffusion de documents scientifiques de niveau recherche, publiés ou non, émanant des établissements d'enseignement et de recherche français ou étrangers, des laboratoires publics ou privés. 


\section{SHS in Ni/Al nanofoils: a review of experiments and molecular dynamics simulations}

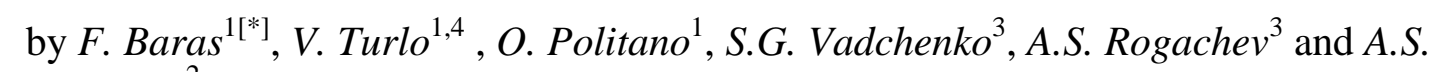
Mukasyan $^{2}$

(1) Laboratoire Interdisciplinaire Carnot de Bourgogne, UMR 6303 CNRS-Université Bourgogne Franche-Comté, 21078 Dijon, France

(2) Department of Chemical and Biomolecular Engineering, University of Notre Dame, Notre Dame, IN 46556, USA

(3) Institute of Structural Macrokinetics and Materials Science, Russian Academy of Sciences, 142432 Chernogolovka, Russia

(4) Nanoscale Mechanics and Materials Laboratory, University of California, Irvine, USA

[*] Corresponding author: fbaras@u-bourgogne.fr

\section{Abstract}

Non-isothermal processes in nanometric metallic multilayers are reviewed, both experimentally and theoretically. The $\mathrm{Ni} / \mathrm{Al}$ nanofoil is considered as a model system. On the one hand, the experimental methods of elaboration and analysis are presented and, on the other hand, the modeling approach at the macroscopic and atomic scale. The basic experimental features are reported together with recent achievements. Molecular dynamics investigation of the reactivity of $\mathrm{Ni} / \mathrm{Al}$ systems is reported for bulk systems and nanosystems including nanoparticles, nanowires, nanofilms and multilayers. The focus is on atomic-scale modeling versus experiments. Molecular dynamics approaches allow us to elucidate the mechanisms of non-isothermal processes occurring in nanoscale systems, such as phase transformations and self-propagation reactions.

\section{Introduction}

Over the past decades, the SHS (Self-propagating High-temperature Synthesis) process has been investigated, amongst others, in the case of reactive multilayer nano-foils (RMNFs) [1]. RMNFs are made up of thin layers of metals A and B deposited alternately. The thickness of each layer may be as small as a few nanometers. The number of layers may vary from tens to thousands. The deposition technique used to produce RMNFs in the form of coating or free- 
standing foils is now well developed. Since the patent obtained by Barbee Jr. and Weihs [2,3] in the year 1996, the interest in these nanomaterials has steadily increased.

A very peculiar property of RMNFs is that a reaction between the pure metals initiated at one edge of the sample, by means of spark or laser, will propagate throughout the system in a selfsustaining way. The heat released locally allows the reaction to proceed without any further supply of energy. The process of reactive wave propagation in RMNFs is schematically depicted in Fig. 1.

RMNFs are used in various applications for joining, brazing or soldering without damaging the materials that have to be joined, or as a heat delivery source $[3,4,5]$. For example, RMNFs composed of nickel and aluminum [3] are used in joining applications as an alternative method to standard processes. The reactive metals are either deposited by magnetron sputtering directly onto the materials to be joined or commercially available as free-standing foils (Nanofoils®). Ni/Al nanofoils are widely used to bond metals and alloys, at room temperature and in air $[6,7]$. Ceramic devices bonding, either to ceramics or to thermally mismatched metallic devices have been realized using $\mathrm{Ni} / \mathrm{Al}$ multilayers [8]. The foils are used for their capability to undergo a self-sustaining exothermic reaction and thus act as a controllable heat source to melt solder. The use of Ni/Al multilayer nanofilms for joining purposes could be significantly improved with a better understanding of the processes involved. Other interesting studies demonstrate that different types of nanolayers are promising in low-temperature brazing applications such as copper-based nanostructured coatings [9]. The SHS-based joining technique opens new application fields such as the joining of thermally and mechanically sensitive materials (i.e. ceramic-metal joints) and the precision joining of microscale components (i.e. MEMS packaging and/or optical components) [10]. 
In this review, we give a concise overview of non-isothermal processes occurring in RMNFs with a special emphasis in the case of $\mathrm{Ni} / \mathrm{Al}$ nanofoils. Both experimental results and modeling approaches are considered. Section 2 gives the experimental methods of elaboration and analysis. In Section 3, the essential features of modeling at macroscopic level and atomic level are presented. The main experimental results of $\mathrm{SHS}$ in $\mathrm{Ni} / \mathrm{Al}$ reactive multilayer nanofoils are reported in Section 4. Molecular dynamics (MD) studies of the reactivity of $\mathrm{Ni} / \mathrm{Al}$ systems are reported in Section 5. The Section 6 is devoted to a comparative study between experimental results and modeling.

\section{Experimental methods}

\subsection{Methods of fabrication of RMNFs}

There are three main preparation methods of RMNFs: (1) vacuum deposition, (2) magnetron sputtering and (3) multiple rolling.

Evaporation deposition: This method is used for the preparation of very thin films with tens of alternating layers, with a total thickness of $30-300 \mathrm{~nm}[11,12]$. It was the original method of producing RMNFs for combustion synthesis. The difficulty of controlling deposition over a long time prevents this method from being used to produce hundreds or thousands of layers. For this reason, high-vacuum electron-beam evaporation is now rarely used in the production of reactive metallic multilayers.

Magnetron sputtering: This method is a very powerful technique for the production of the metallic nanofoils with thousands of alternating layers [3]. This method allows for the deposition of layers of constant thickness. The magnetron sputtering method is schematized in Fig. 2. Alternating layers of reactants are deposited on the substrate from two sources of atoms impacted by a plasma of inert gas leading to the formation of a flux of atoms in the direction of the substrate. The holder of the substrate layer is rotated and the number of A-B bilayers is equal to the number of the rotations. The thickness of each layer is determined by 
the rotation speed, the source power and the distance between source and substrate. Sputtering is usually performed at room temperature in order to reduce the effect of mutual diffusion between layers during deposition. Water cooling is commonly required to keep substrates cold during deposition. RMNFs of many systems, such as Ni/Al, Ti/Al, Nb/Al, Ta/Al, $\mathrm{Cu} / \mathrm{Al}$, have been produced by the method of magnetron sputtering and the SHS process has been studied in these nanofilms [1]. Magnetron sputtering is currently the main method used to produce high-quality RMNFs for experimental purposes. The main drawbacks of this method are its relatively slow production speed and high cost.

Multiple rolling: This method is the most efficient and cheapest alternative of the deposition methods. The method, which is still in its developing stage, is based on the idea of a multiple rolling-stacking process, which is illustrated in Fig. 3. First, the initial thin films of A and B metals are alternatively packed, pressed and annealed. After that, the film is rolled to reduce the thickness and then folded. The process is repeated many times.

This procedure was used to prepare of the RMNFs in the Ni/Al system by performing up to 70 of the rolling-stacking cycles [13]. Thin stripes with a thickness of smaller than $100 \mathrm{~nm}$ were observed with an irregular microstructure. Recently, multiple cold rolling without annealing stage was developed for producing the Ni/Al reactive foils [14]. Bilayer thickness 2 -14 microns were obtained depending on the numbers of the repeating rolling, and possibility of self-propagating reaction was demonstrated for the foils with bilayer thickness up to 7 microns. The rolling of thin films in the $\mathrm{Pt} / \mathrm{Al}$ system gives a more regular microstructure [15]. Nevertheless, the nanofoils, prepared by means of the multiple rolling method, consist of noncontinuous and imperfect layers with additional stress and defects. At this time, the method needs to be improved to produce RMNFs with a regular structure.

\subsection{Methods of Analysis}

[Tapez le titre du document] / p 4 
Two kinds of experiments are usually performed to study the SHS process in RMNFs: (1) reactive wave propagation in free-standing foils; (2) reactive wave propagation with quenching of the reactive front. Experiments with free-standing foils provide information about the characteristics of the SHS wave propagation, such as the wave propagation velocity, the combustion temperature, etc. The experimental set up with a free-standing foil is shown in Fig. 4. Holder and weight keep the foil immobile during the time of the experiment. A high-speed color video camera records the reactive wave propagation. Then, the frame-byframe analysis of the position of the reaction front allows calculation of the propagation velocity. The description of the wave propagation in Ni/Al RMNFs is reported in Section 4. Following the brightness of a small region gives the temperature-time evolution (thermogram). Photo-diodes provide another, more accurate, way to determine the thermogram, because the photo-diode is sensitive to infrared radiation, when the temperature is relatively low. In addition, the temperature-time profiles, obtained by the above methods, can be calibrated using W-Re micro-thermocouples. A comparison of all these methods is discussed in the case of the equiatomic Ni/Al nanofoil in [16]. Due to the high propagation velocities, direct study of the microstructure of the reaction zone is difficult. The quenching method is used to follow the microstructure transformations during the SHS wave propagation. The general scheme is given in Fig. 4b. A multilayered nanofoil is stacked with a massive copper block on one side and with a transparent quartz block on the other side. Due to the extremely high conductive heat losses, the combustion front slows down and stops at some point. The quenched front was analyzed by Scanning Electron Microscopy (SEM) and Transmission Electron Microscopy (TEM) in order to obtain the microstructure from microns to nanometer. Diffraction techniques are used to determine the local composition along the front. On the other hand, in situ observations within the dynamic TEM have revealed microstructure changes and local melting events during reaction propagation $[17,18,19]$. 


\section{Modeling approach}

\subsection{Macroscopic modeling of the SHS wave propagation in RMNFs}

In an RMNF, the front propagation direction is parallel to the interfaces, as shown in Fig. 5. In this case, the wave propagation process is described by the reaction-heat conduction equation in $3 \mathrm{D}$

$$
\rho c_{p} \frac{\partial T}{\partial t}=\nabla \cdot(\lambda \nabla T)+\phi(T, C)
$$

coupled with the diffusion equation

$$
\frac{\partial C}{\partial t}=\nabla \cdot(D \nabla C)
$$

where $\nabla$ is the Laplace operator, $\rho$ is the density, $c_{p}$ is the heat capacity, $\lambda$ is the heat conductivity, $C$ is the reactant concentration, $\phi$ the heat source function, and $D$ is the diffusion coefficient. Generally, the concentration is normalized by one half of the pure A concentration. The value of $C$ is in between 0 (pure B) and 2 (pure A). The value of $C=1$ refers to the full mixing of reactants. In the simplest model, the one we present here, only the mixing of reactants is taken into account. A full mixing corresponds to the completion of the reaction. In other words, it is assumed that $\mathrm{A}$ and $\mathrm{B}$ reactants have a positive heat of mixing and that mixing is limited by the diffusion of reactants across the layers. In 1990, Armstrong was the first to formulate the problem of solid combustion in multilayered systems in such a way [20].

Figure 5 depicts the main characteristics of the front. The front does not correspond to a sharp variation in the concentration. The magnification of the front zone shows a zigzagged local profile associated with the propagative mixing of $\mathrm{A}$ and $\mathrm{B}$ as a function of temperature. The typical profile of concentration $C$ along the system is represented in the three insets: (a) $C=1$ for a complete mixing; (b) a smooth variation of $C$ from 0 to 2 in the reaction zone; (c) a step function for unreacted layers. Using a singular perturbation theory based on the large 
activation limit, Armstrong [20] succeeded in obtaining an analytical expression for the front velocity given by

$$
v=\frac{4 \alpha T_{c}}{H}\left(\frac{3 k R}{E\left(T_{c}-T_{0}\right.}\right)^{1 / 2} \exp \left(-\frac{E}{2 R T_{c}}\right)
$$

where $k$ is an Arrhenius prefactor, $E$ is the activation energy for mass diffusion, $R$ is the gas constant, $\alpha=\lambda / \rho c_{p}$ is the thermal diffusivity, and $H$ is the bilayer thickness. The characteristic temperatures are the initial temperature $T_{0}$ and the combustion temperature $T_{c}$. The inverse dependence of the front velocity on the bilayer thickness $H$ is an essential feature observed in experimental works, whatever the system, as shown in Fig. 6. Nevertheless, the bilayer thickness is not the only feature that affects the reactive front velocity. Other features such ignition condition (Fig. 6.(1-2)), annealing time and temperature (Fig. 6.(3-6)), total multilayer thickness (Fig. 6.(7-11)), stoichiometry (Fig. 6.(12-13)) also modify the measured velocity. However, there is the one common observation for almost all the systems: the velocity is maximum for a bilayer thickness of less than $50 \mathrm{~nm}$. For smaller values, the velocity slightly decreases. In 1997, Mann et al. [21] proposed an explanation for this behavior based on the existence of a premixed interfacial layer. They developed a model based on the Armstrong's approach and derived an analytical solution for the front velocity

$$
v=f(H) \frac{\alpha T_{c}}{2}\left(\frac{k R H}{E\left(T_{c}-T_{0}\right)}\right)^{1 / 2} \exp \left(-\frac{E}{2 R T_{c}}\right)
$$

where the function $f(H)$ depends on the deviation of the initial composition from the ideal one (step function) as derived in [4,21]. The existence of a premixed interfacial layer was confirmed experimentally by transmission electron microscopy [21,22]. Nevertheless, the extended model includes several parameters, such as the premixed layer thickness, the initial concentration profile (linear, parabolic, exponential, etc.), which can be variated in a wide range. The extended model is mainly used for the fit of experimental data and for parameter estimation. To increase the accuracy of calculations, the main characteristics of a studied 
system, such as the nature of the preliminary and final products, their stoichiometry, diffusivity and so on, have to be taken into account.

Based on the model introduced by Mann et al. [21], the continuum approach to describe combustion wave propagation in Ni/Al multilayers was further developed by Besnoin et al. [23] in 2002. In their model, the reactive wave propagates due to the intermixing of $\mathrm{Ni}$ and $\mathrm{Al}$ through the $\mathrm{B} 2-\mathrm{NiAl}$ intermetallic phase. Intermixing layers refer to the initial premixing in the as-deposited state. The heat conduction equation is replaced by an equation for the enthalpy field that accounts for the possible melting of the reactants and products. Next, a reduced model was proposed by Salloum and Knio [24] in 2010 to simplify the continuum model proposed by [23]. The optimal parameters of the pre-exponential factor and the activation energy, $D_{0}=1.9110^{-6} \mathrm{~m}^{2} / \mathrm{s}$ and $E=97.1 \mathrm{~kJ} / \mathrm{mol}$, were obtained by Alawieh et al. [25] from this reduced model in 2013.

It is important to note that most of these models are based on growth of an intermetallic phase between two solid reactants and ignore the influence of the dissolution of one component into another. And yet, the dissolution process plays a crucial role in binary systems in which one of the reactants has a lower melting temperature than the other (like Al-based N2M, for example $\mathrm{Ni} / \mathrm{Al}$ or $\mathrm{Ti} / \mathrm{Al})$. Various experimental findings support this affirmation. Experiments on Al-based multilayers indicate that the reaction may start at low temperature (near $300^{\circ} \mathrm{C}$ ) but propagates at a temperature close to the melting temperature of aluminum. In some cases, this temperature can be even lower, due to the melting point depression observed in nanometric layers [26]. The reaction thus occurs in a solid/liquid system. If the metallic reactants are miscible, the dissolution of the less refractory metal into the liquid leads to an intermixing with substantial heat release. Experiments show that intermixing produces up to $60 \%$ of total heat release. The efficiency of mixing at interfaces is directly related to the nature of the premixing layer. The nature of the premixing layer is of crucial importance in 
the development of the reactive processes. If the interfacial region consists of an intermetallic phase, the dissolution is hindered by the thin product layer between the reactants. The existence of such a product layer between the reactants is, however, open to question. Indeed, XRD analysis of "as-deposited" N2M showed no intermetallic phase in the intermixed region between the reactants, although TEM reveals some intermediate layers. The intermixed region probably contains a solid amorphous phase, which can easily be dissolved after the melting of the Al layer. Finally, the estimation of diffusion coefficients during reaction in N2M shows that their order of magnitude is typical of liquids or melts $[16,27]$.

A generalized model for the reactive wave propagation in RMNFs, which takes into account the melting of one component, was formulated by Makino [28] in 2003. The front velocity was found to be inversely dependent on the layer thickness of the reactant with the higher melting point. The effect of the heat loss was also examined: combustion front velocity decreases with the increase in the heat loss.

A numerical model based on the diffusion-limited dissolution [29] coupled with heat transfer by conduction has been derived by Turlo et al. [30] to account for the main aspects of the dissolution-driven reactive wave propagation in the Ni/Al RMNFs. This model involves two coupled equations for the temperature and the mole fraction of $\mathrm{Ni}$ in the liquid layer, with an explicit heat release function associated with the exothermic dissolution. Turlo et al. have obtained an analytical expression for the front velocity in a following form:

$$
v=f \cdot T_{c}^{2} \exp \left(-\frac{E}{R T_{c}}\right)
$$

where $f$ is a complex function of the system's properties (thermal diffusivity, heat release by dissolution, solubility limit, etc.) and parameters (initial temperature, bilayer thickness, stoichiometry, etc.). Typically, the activation energy $\mathrm{E}$ obtained from the linear fit $\log \left(v / T_{c}^{2}\right) v s .1 / T_{c}$ corresponds to the activation energy of interdiffusion in a solid-liquid system. This model was successfully applied by Turlo et al. to analyze of the MD simulations 
and experimental results. The exothermic intermixing of $\mathrm{Ni}$ and $\mathrm{Al}$ in the liquid layer appears as the main mechanism driving the self-sustaining propagation in the reactive $\mathrm{Ni} / \mathrm{Al}$ nanofoils. In-situ studies, both XRD and DTEM, support this hypothesis [17,18,19]. Moreover, by investigating the applicability of the model, Turlo et al. demonstrated that the reactive dissolution of $\mathrm{Ni}$ into liquid $\mathrm{Al}$ may be the only driving mechanism for propagation in the case of equiatomic Ni/Al RMNFs with a bilayer thickness less than $54 \mathrm{~nm}$.

\subsection{Atomic-scale description}

Over the past decades, the progress in computing facilities allowed to perform atomic-scale simulations to study the structure and thermo-mechanical properties of nanomaterials. One of the most useful atomic approaches is provided by molecular dynamics simulations (MDS), in which the evolution of a set of atoms or molecules is followed. Since the pioneering work by Alder in 1957 on the melting and crystallization of hard spheres [31], the number of MD studies in physics, chemistry, biology and materials science has increased exponentially. For nanometric metallic multilayers, MD is a very appropriate method for numerical studies, as the accessible time and length scales are in the same range of magnitude as in "real" experiments.

\subsubsection{Method}

The MD method is based on the integration of the Newton's second law of motion for a set of atoms. At the initial time, the position and the velocities of the particles/atoms are defined. Initial velocities are usually chosen randomly from a given distribution function (e.g. Gauss, Maxwell-Boltzmann, etc.) at the desired temperature. Periodic boundary conditions are applied to model infinite bulk systems whereas, fixed or shrink-wrapped boundaries are considered to study, for example, the presence of a surface or the behavior of a finite-size system. Different thermodynamic ensembles are available to perform MD simulations. Among them, the micro-canonical ensemble (NVE) with a constant number of atoms $\mathrm{N}$, 
volume $\mathrm{V}$ and total energy of the system $\mathrm{E}$, corresponds to an adiabatic (isolated) system. The canonical ensemble (NVT) describes a system in thermal equilibrium with a heat bath at a given constant temperature $\mathrm{T}$. The interaction of the system with its environment is performed by adding an effective dissipative force as in the Nosé-Hoover thermostat $[32,33]$. This approach was further extended by Parinello and Rahman to consider the isothermal-isobaric (NPT) ensemble with constant pressure $\mathrm{P}$ and temperature $\mathrm{T}[34,35,36]$. Finally, in the isoenthalpic (adiabatic)/isobaric ensemble (NPH) the number of atoms $(\mathrm{N})$, the total pressure $(\mathrm{P})$ and the enthalpy $(\mathrm{H})$ are maintained constants [37].

Many techniques are available to solve Newton's differential equation (Verlet, velocityVerlet, leap-frog, predictor-corrector, ...) [37,38] and the choice of an integrator results from a compromise between its computational efficiency and its capacity to handle long time steps without deviating significantly from the path of the "exact" trajectory. All these features are implemented in MD packages such as the open-source Large-scale Atomic/Molecular Massively Parallel Simulator, LAMMPS, developed by Plimpton [39] since 1995.

\subsubsection{Interatomic potentials}

In classical MD, the forces on the atoms are determined from the gradient of the potential energy defined by an empirical interatomic potential. For metallic systems, many-body potentials such as the Finnis-Sinclair (FS) [40] and embedded-atom methods (EAM) [41] potentials have been developed since the 80 's. Both formalisms incorporate a two-body repulsive term and a many-body (binding) term describing the variation in the electron density of each atom depending on the environment of the neighboring atoms. They include adjustable parameters determined so as to reproduce physical quantities known experimentally or derived from ab initio calculations (cohesive energy, atomic volume, elastic constants, phonon frequency, forces, surfaces and relaxation energies, lattice parameters, etc.). FS and EAM potentials have been successfully used to study many metallic systems, 
such as $\mathrm{Al}[42,43,44]$, Ni [42,44,45], $\mathrm{Cu}[45,46], \mathrm{Au}[45], \mathrm{Fe}$ [47]. For the Ni-Al system, many interatomic potentials have been developed to study the structural, thermodynamic and atomic-transport properties of solid and liquid Ni-Al alloys and compounds $[42,48,49,50,51,52]$. The fit of a potential is based on a compromise between the accurate description of some specific properties and the transferability to others ones that are not directly considered in the fitting procedure. As an example, three different versions of an NiAl potential developed by Y. Mishin and co-workers [49,53,54] were considered in [55]. All versions reproduce well the structural properties of the solid and liquid phases and the composition dependence of the atomic volume in the liquid phase. Thermodynamic properties, like enthalpies of the solid and liquid phases, play an important role in accurate determination of adiabatic and combustion temperatures (see [1,30]). Based on the computations reported in [55], the [49] potential is the less accurate to use in this context as the melting temperatures exhibit a high level of discrepancy compared to experimental values, although the sequence of melting temperatures is preserved. In the case of the EAM-09 potential [54], the melting temperatures are closer to the experimental values. It is well suited to simulate equiatomic $\mathrm{Ni} / \mathrm{Al}$ systems, where formation of the $\mathrm{B} 2-\mathrm{NiAl}$ intermetallic phase is expected. The EAM-04 potential [53] is more appropriate in $\mathrm{Al} / 3 \mathrm{Ni}$ systems, where the L12$\mathrm{Ni}_{3} \mathrm{Al}$ intermetallic phase can be formed. As an example, the enthalpy of mixing is computed for different EAM potentials and compared to the experimental values in Fig. 7.

\subsubsection{Analysis tools}

MD output consists of individual atomic properties (position, velocities, energies, species,...). These raw data need to be post-processed in order to obtain a microscopic view of the system at each time. Beyond direct visualization of the atomic positions (snapshots) with a tool such as the open-source software OVITO [56], it is often necessary to separate atoms not only by chemical species, but also by local atomic structure. Many methods have been developed to 
distinguish atoms by cohesive energy $[57,58]$, coordination, common neighbor analysis $[59,60]$ or centrosymmetry [61]. They usually refer to the ideal structures of bcc, fcc, hcp or icosahedral. Among all these methods, the Ackland and Jones analysis [62] is based on the angle distribution of the nearest neighbors of each atom and is not as sensitive to thermal fluctuations as the other methods. However, when applied to study coexisting liquid/solid systems it identifies many artificial "crystalline" atoms inside the amorphous liquid. To overcome this spurious effect, we modified the standard analysis in order to clearly distinguish atoms belonging to either the solid or the liquid phases. This modification thereby provides a useful tool to follow the nucleation and growth of the new crystalline phase inside a liquid [29].

The number density profile (NDP) is also a useful tool for analyzing simulation data, especially in multiphase systems. For example, the effect of a planar ordering of the liquid alloy close to the crystal-liquid interface can be observed from NDP [63]. The formation of new crystalline phases can also be followed by using NDPs at different times, as done in Section 6.1.

When we consider the growth of grains on a substrate, it is interesting to compute the crystallographic texture. That is the relative orientation of the new phase with respect to the surface. For each atom in a specific grain, we identified the first shell of atoms of the same species. In this shell of atoms, two-by-two alignments will define a local crystallographic frame. The rotation matrix which embodies the rotation of the sample coordinates onto the crystal (grain) coordinates is then computed. The method allowed us to get the Euler angles and the Miller indices of a collection of grains with respect to the sample [64]. 


\section{Experimental study of the SHS process in Ni/AI RMNFs}

\subsection{Basic experimental facts}

The Ni/Al multilayer is often used as a model system and as such it has been widely investigated. The SHS reaction at the nanoscale can be triggered at relatively low temperature (480$540 \mathrm{~K}$ for $\mathrm{Ni} / 3 \mathrm{Al}$ films $[65,66]$, about $500 \mathrm{~K}$ for $\mathrm{Ni} / \mathrm{Al}[67,68]$ ) and the propagation speed is high compared to the process in micrometric metallic powders $(1-10 \mathrm{~m} / \mathrm{s}$ for the $\mathrm{Ni} / \mathrm{Al}$ RMNFs [4,69] and 1-10 mm/s for the Ni/Al powder mixture [70 ]). The elemental mechanisms responsible for these properties are not completely understood. For miscible metals such as $\mathrm{Ni}$ and $\mathrm{Al}$, the energy released during the reaction is either associated with the mixing (positive heat of mixing) or with the formation of intermetallic compounds. A large number of possible intermetallic compounds can be formed in the Ni/Al system (see the nickel-aluminum phase diagram in Fig. 8); all of which can be synthesized by SHS.

Dyer and Munir [71] performed experiments on SHS wave propagation in Ni/Al and 3Ni/Al RMNFs, forming the $\mathrm{NiAl}$ and $\mathrm{Ni}_{3} \mathrm{Al}$ compounds, respectively, as final products. The measured velocity is dependent on the bilayer thickness as expected in the framework of Armstrong's model. Using the explicit form (4), the effective activation energies were estimated in the ranges from 127.9 to $149.8 \mathrm{~kJ} / \mathrm{mol}$ for $\mathrm{Ni} / \mathrm{Al}$ and from 133.8 to $146.3 \mathrm{~kJ} / \mathrm{mol}$ for $3 \mathrm{Ni} / \mathrm{Al}$ multilayers.

Gavens et al. [4] studied the effect of annealing time and bilayer thickness on SHS wave propagation in $2 \mathrm{Ni} / 3 \mathrm{Al} \mathrm{RMNFs}$, with the formation of the $\mathrm{Ni}_{2} \mathrm{Al}_{3}$ intermetallic compound. They estimated the values of the thickness of the intermixed layer for several annealing periods. They observed an increase in this thickness from $1.2 \mathrm{~nm}$ in the as-deposited state to $9.2 \mathrm{~nm}$ after 24 hours of annealing. The propagation front velocities were analyzed using the Mann et al. [21] approach for RMNFs with initial premixing. The fit of the experimental 
values by eq. (4), adapted for $2 \mathrm{Ni} / 3 \mathrm{Al}$ stoichiometry, gives the activation energy of 145.8 $\mathrm{kJ} / \mathrm{mol}$.

From the other hand, good correlation between theoretical lamellar reaction diffusion models and experimental results on combustion propagation velocity can be achieved only if we assume diffusion coefficient that is significantly higher than diffusivity of $\mathrm{Ni}$ or $\mathrm{Al}$ in solid intermetallics $\left(\mathrm{NiAl}_{\mathrm{x}}\right)$. It is known that "classical" reaction diffusion model assumed that diffusion of the reactants through a continuous layer of solid product, which is formed on the boundary between the layers, controls the combustion wave propagation [ 72,73 ]. Modifications of the lamellar model developed specially for the RMNFs, assume only formation of a continuous intermixed layer, without specification of the phase constitution of this layer: it may be a liquid or solid solution, or an intermetallic compound [4,21,24]. An alternative model of reactive dissolution suggests that macrokinetics of the combustion process is limited by the rate of solid $\mathrm{Ni}$ dissolution in liquid $\mathrm{Al}$ [27], which explains high diffusivity coefficients. Experimental results showed that the first leading stage of the combustion wave propagation relates to dissolution, and the wave temperature profile consists of two stages $[16,74]$. This conclusion was made basing on temperature profiles of reaction waves measured by photo-diode, high-speed video camera, and micro-thermocouple. In all cases, duration of the first stage of heat release was less than $1 \mathrm{~ms}$, which is much shorter than the second one (tens to hundreds of milliseconds). Microstructure of the reaction zone presented in Fig. 9 shows that the crystalline product consists of separate grains and does not form a continuous layer. The channels of melt, remaining between the grains, allow direct dissolution of the Ni in liquid Al. This microstructure correlates well with results of molecular dynamic simulation, as illustrated in Section 6.

Sequences of several intermediate phases were suggested for the reaction $\mathrm{Ni}+\mathrm{Al}$ in $\mathrm{RMNFs}$ basing on the results of differential scanning calorimetry [65]. The DSC method also showed 
that the exothermal reaction initiated at temperature much below any melting or eutectic point in the system Ni-Al. It should be noted that a new method of nanocalorimetry [75] allows much faster heating rated that common DSC. Heating rates up to $10^{4}-10^{5} \mathrm{~K} / \mathrm{s}$ achieved in the microcalorimetric study of $\mathrm{Ni} / \mathrm{Al}$ RMNFs led to conclusion that high heating rate in the nanocalorimeter suppresses the formation of intermediate metastable phases; nevertheless, formation of intermediate $\mathrm{Al}_{3} \mathrm{Ni}$ and $\mathrm{Al}_{3} \mathrm{Ni}_{2}$ was detected [76,77]. An important detail of the microcalorimetry study is that temperature always remained below melting point of $\mathrm{Al}$ (933 $\mathrm{K})$, therefore, reaction of the solid $\mathrm{Ni}$ with Al-melt was excluded in advance. Under conditions of very fast heating in the combustion front, temperature rises very fast beyond the melting temperature of $\mathrm{Al}$, and only one crystalline phase $\mathrm{NiAl}$ appears. That was confirmed by Time-Resolved Synchrotron-Rays Diffraction [78] and Time-Resolved TEM [17,18,19].

Thus, we can summarize main experimental facts known about Ni/Al RMNFs in the following points:

$\checkmark$ Self-propagating reaction in the Ni/Al RMNFs can be initiated at temperature about $500 \mathrm{~K}$, much below melting temperature of $\mathrm{Al}(911 \mathrm{~K})$. Upon initiation, the reaction generates heat that immediately increases the temperature to above the melting point of $\mathrm{Al}$.

$\checkmark$ Propagating rate of exothermic reaction is about 2 orders of magnitude higher in comparison with powder samples of similar $(\mathrm{Ni}+\mathrm{Al})$ composition.

$\checkmark$ Propagating rates depends on the bilayer thickness in the range 5-1000 nm, with a strong maximum in the vicinity of $25 \mathrm{~nm}$.

$\checkmark$ Temperature-time profiles of the reaction wave reveal two stages of heat generation.

$\checkmark$ The first, very fast ( $1 \mathrm{~ms}$ or less), stage of combustion process relates to dissolution of solid $\mathrm{Ni}$ in molten $\mathrm{Al}$ and crystallization of $\mathrm{NiAl}$. 
Intermediate phases appear, if the heating rate is low (e.g., DSC, etc.) or the temperature does not achieve melting point of aluminum (e.g., nanocalorimetry).

\subsection{Recent achievements and problems remaining}

Further development of RMNFs moves along three general directions: (a) creating new combinations of reactants or methods of production, (b) deeper understanding mechanism of the process, and (c) novel applications. Systems that have higher exothermal effect than the $\mathrm{Ni} / \mathrm{Al}$ often involve thermites, such as combination of metal oxides with aluminum. However, intense evaporation of $\mathrm{Al}$ and other metals during highly exothermic thermite reactions becomes a problem for most of applications (soldering materials, etc.). In order to suppress gas generation and avoid pore formation during the exothermic reaction, diluted reactive multilayer $\mathrm{Al}-\mathrm{Cu}-\mathrm{Cu}_{2} \mathrm{O}-\mathrm{Cu}$ thin films were produced via magnetron sputtering [79]. The excess $\mathrm{Cu}$ layers act as diffusion barriers, limiting the transport of oxygen from the oxide to the $\mathrm{Al}$ fuel, and decrease temperature of the self-propagating thermite reactions below the boiling point of $\mathrm{Cu}$, eliminating metal vapor production. Another example of a new composition is an aluminum/molybdenum trioxide $\left(\mathrm{Al} / \mathrm{MoO}_{3}\right)$-based $\mathrm{RMNFs}$ with different modulation periods that were produced using an image reversal lift-off process and magnetron sputtering technology [80]. These RMNFs were integrated into microchip initiators that proved to have tunable ignition performance, which can potentially be used in civilian and military applications. . It is worth noting that multilayer nanothermite system $\mathrm{Al} / \mathrm{CuO}$ was applied earlier for creating the microchip initiators [81, 82]. In addition to magnetron sputtering, mechanical processing of the thermite-type RMNFs are developing, including Al$\mathrm{Cu}_{2} \mathrm{O}-\mathrm{Cu}$ [83] or $\mathrm{Al}-\mathrm{NiO}, \mathrm{Al}-\mathrm{CuO}$ and $\mathrm{Al}-\mathrm{Cu}_{2} \mathrm{O}$ systems [84]. Some new mechanical approaches, like radial forges, have been applied to the $\mathrm{Ni}$-Al system in order to produce dense reactive materials [85]. In the field of systems with elemental components (reactions of 
synthesis from elements), research also continues. Some new results were obtained for methods of ignition of high-exothermic $\mathrm{Al} / \mathrm{Pt}$ foils by pulsed-laser irradiation [86] and features of low-exothermic Ti/Al RMNFs with tuned layers thickness [87]. Interesting results were obtained for magnetron sputtered deposited ternary reactive films with two different multilayer arrangements of $\mathrm{Ti} / \mathrm{Si} / \mathrm{Ti} / \mathrm{Al}$ and $\mathrm{Si} / \mathrm{Ti} / \mathrm{Al} / \mathrm{Si}$ with the identical bilayer of $29 \pm 5 \mathrm{~nm}$ and total thickness of $6 \mu \mathrm{m}$ [88]. Exothermic reaction front propagated in the Ti/Si/Ti/Al films with steady state velocity of $9.1 \pm 2 \mathrm{~m} / \mathrm{s}$ and the maximum reaction temperature of 1768 $\pm 41{ }^{\circ} \mathrm{C}$. Steady state and unsteady propagation modes were observed in $\mathrm{Si} / \mathrm{Ti} / \mathrm{Al} / \mathrm{Si}$ reactive foil, with a maximum reaction velocity of $2.7 \pm 0.8 \mathrm{~m} / \mathrm{s}$. Although both ternary films have similar reactant types and morphology, different reactant interfaces introduce the distinct interfacial reactions and local atomic mixing rates, which influence the reaction characteristics. The possible explanation is that intermixing of elements in the vicinity of interfaces differs for the two cases: deposition of Ti atoms on the surface of solid Si layer, and deposition of Si atoms on the surface of Ti layer. This research also shows a new opportunity to design nanoscale reactive films with different multilayer arrangements to control reaction propagation beyond existing technology [88]. A comparative study of the reaction multilayer foils $\mathrm{Ni} / \mathrm{Ti}$, produced by two different methods, magnetron sputtering and accumulative roll bonding, were carried out [89]. Reliable joints of TiNi to Ti6Al4V were obtained, with shear strength of $35 \mathrm{MPa}$ in case of accumulatively rolled foils, and $88 \mathrm{MPa}$ when magnetron sputtered foils were used.

The $\mathrm{Ni} / \mathrm{Al} \mathrm{RMNFs}$ remain in the focus of experimental research aimed at understanding reaction mechanisms in multilayer nanofilms. Detailed study of sequence of phase formation carried out using DSC and in situ TEM showed that slow heating results in consecutive formation of $\mathrm{Al}_{3} \mathrm{Ni}, \mathrm{Al}_{3} \mathrm{Ni}_{2}$ and $\mathrm{NiAl}$ [90]. The average grain size of $\mathrm{NiAl}$ phase produced by slow heating (DSC) was comparable with the $\mathrm{Ni}(\mathrm{V}) / \mathrm{Al}$ multilayer period, about $50 \mathrm{~nm}$, 
whereas in the case of reaction initiated with electric pulse (fast heating) the grain size of single phased $\mathrm{NiAl}$ was in the micrometer range. Direct observation of grains nucleation and growth by means of in-situ TEM slow heating experiments showed that while the intermediate $\mathrm{Al}_{3} \mathrm{Ni}$ and $\mathrm{Al}_{3} \mathrm{Ni}_{2}$ phases nucleate at $\mathrm{Ni}(\mathrm{V}) / \mathrm{Al}$ and $\mathrm{Ni}(\mathrm{V}) / \mathrm{Al}_{3} \mathrm{Ni}$ interfaces, respectively, the final $\mathrm{NiAl}$ nucleates throughout the intermixed $\mathrm{Al}_{3} \mathrm{Ni}$ and $\mathrm{Al}_{3} \mathrm{Ni}_{2}$ (original Al) layer [91]. The growth of the $\mathrm{Al}_{3} \mathrm{Ni}$ crystallites proceeds by a moving planar front along the $\mathrm{Al}$ layer changing the $\mathrm{Ni}(\mathrm{V}) / \mathrm{Al}$ into $\mathrm{Ni}(\mathrm{V}) / \mathrm{Al}_{3} \mathrm{Ni}$ multilayers. The growth of $\mathrm{Al}_{3} \mathrm{Ni}_{2}$ crystallites looks like coarsening of rounded precipitates. The growth of final NiAl phase is much faster than $\mathrm{Al}_{3} \mathrm{Ni}_{2}$ and results in formation of a string of cubical crystallites separated by a discontinuous layer of fine $\mathrm{Al}_{8} \mathrm{~V}_{5}$ crystallites. It was concluded that described series of phase transformations might be considered as a model for solid state diffusion controlled reaction of $\mathrm{Ni} / \mathrm{Al}$ multilayers [91]. Formation of intermediate phases, such as metastable $\mathrm{Al}_{9} \mathrm{Ni}_{2}$ and $\mathrm{Al}_{3} \mathrm{Ni}$ was confirmed for reactive $\mathrm{Ni} / \mathrm{Al}$ multilayer films produced by electronbeam physical vapor deposition [92]. Later on, $\mathrm{Al}_{9} \mathrm{Ni}_{2}$ and $\mathrm{Al}_{3} \mathrm{Ni}$ phases turn into stable intermetallic in accordance with the RMNFs composition.

A novel technique based on X-ray reflectivity was developed for measuring interdiffusion in the multilayer materials during rapid heating [93]. The multilayer Ni/Al sample was bent to achieve a range of incident angles simultaneously and heated at rates up to $200 \mathrm{~K} / \mathrm{s}$ by electrical resistive heating of the silicon substrate, while the scattered intensity was recorded on a fast high-dynamic-range mixed-mode pixel array detector. At short times the interdiffusion coefficient can be determined from the rate of decay of the reflectivity peaks, and it was shown that the activation energy for interdiffusion is consistent with a grain boundary diffusion mechanism. However, at longer times this simple analysis is not applicable since the evolution of the reflectivity pattern is complicated by other processes, such as nucleation and growth of intermetallic phases. New modifications of known methods 
of kinetic research, such as thermal dilution of reactive systems, were recently reported in order to vary temperature of reaction and reveal activation energy. For example, a new class of reactive materials termed "inert-mediated reactive multilayers" (IMRMs) that use inert material to decouple the effects of chemistry and maximum temperature in a reactive multilayer have been presented [94]. A set of IMRMs fabricated using 23-nm-bilayer 1:1 Al:Ni reactive sections and 2:3 Cu:Ni inert sections was tested. Due to the thermal dilution, all IMRM samples undergo the same net reaction $(\mathrm{Al} / \mathrm{Ni} \rightarrow \mathrm{AlNi})$ but at a range of different flame temperatures (roughly $1950 \mathrm{~K}$ to $1300 \mathrm{~K}$ ). Using existing theoretical models for the relationship between flame temperature and propagation velocity, the values of activation energy for the process were calculated. At high reaction temperatures, very low activation energy equal to $26 \mathrm{~kJ} / \mathrm{mol}$ was obtained, which suggests diffusion of $\mathrm{Ni}$ in molten $\mathrm{Al}$ is the rate controlling mixing mechanism in agreement with the conclusions of other studies focused on un-mediated $\mathrm{Al} / \mathrm{Ni}$ reactive multilayers. However, as the reaction temperature decreases the activation energy appears to shift to much larger values implying a change in the reaction mechanism, which indicates that solid products are able to form earlier in the reaction at these temperatures, impeding atomic diffusion and intermixing [94]. One more novel method designed for investigation mechanisms of $\mathrm{N} 2 \mathrm{M}$ reactions, that should be mentioned here, is a unique non-adiabatic bomb calorimeter to measure heat generated by nanocomposite metallic foils [95]. Reactions are initiated with a low-energy electrical spark and can be performed in 1 atm of air, oxygen, nitrogen, or argon, in order to investigate reaction and burning characteristics in various environments. Calibrations performed in argon using equimolar $\mathrm{Ni} / \mathrm{Al}$ nanocomposite foils displayed the possibility of measuring heat generation on the order of tens of Joules released by milligram range samples.

Solid-state reactivity of the Ni/Al RMNFs can be significantly increased after irradiating the foils by carbon and aluminum ion beams [96]. Relatively short, 40 min or less, 
ion irradiation significantly decreases self-ignition temperatures and ignition delay time; these results may shed some light on the reaction mechanism. TEM studies shown that irradiation leads to atomic mixing at the $\mathrm{Al} / \mathrm{Ni}$ interfaces with the formation of an amorphous interlayer, in addition to the nucleation of small $(2-3 \mathrm{~nm}) \mathrm{Al}_{3} \mathrm{Ni}$ crystals within the amorphous regions. It was suggested that the amorphous interlayer enhance the reactivity by increasing the heat of the reaction and by speeding the intermixing of $\mathrm{Ni}$ and $\mathrm{Al}$, while the small $\mathrm{Al}_{3} \mathrm{Ni}$ crystallites facilitate growth of this intermetallic phase. In contrast, longer irradiations decrease reactivity with higher ignition temperatures and longer ignition delay times, which may be associated with growth of the $\mathrm{Al}_{3} \mathrm{Ni}$ intermetallic and decreases in the heat of reaction [96].

All the works considered above were aimed at mechanistic study of the reactions and phase formation in the Ni/Al RMNFs and contribute to further development of various applications for reactive multilayer nanofilms. The most advanced and well-developed application of the Ni/Al nanofoils is joining of dissimilar and heat-sensitive materials, such as the Indium Corporation suggested industrial-scale process called NanoBonding ${ }^{\circledR}$ for soldering magnetron targets ( $\mathrm{Ni}$, ceramics, etc.) to backing plates (brass) using multilayer $\mathrm{Ni}(\mathrm{V}) / \mathrm{Al}$ reactive nanofoils (trade mark NanoFoil@) [97]. The NanoBonding allows target bonders and target manufacturers to make reliable and repeatable bonds while increasing margins and lowering capital expenditures. Among other potential applications, electronic assembly (join components together without exposing components to reflow temperatures), thermal management (solder a component, circuit board or a heat spreader directly to a heat sink to achieve thermal performance 6 to 8 times better than other technologies), and energetics applications (propellant ignition, munitions and circuit protection) are suggested [97]. Recent publications that appear in this field, usually suggest new combinations of dissimilar materials to be joined and/or variations of the joining technique. Thus, in contrast to the standard NanoBonding ${ }^{\circledR}$ process that occurs at room temperature during a very short 
time, a "transient liquid phase diffusion bonding" of $\mathrm{Al}_{2} \mathrm{O}_{3}$ ceramic and copper using $\mathrm{Al} / \mathrm{Ni}$ multilayers was carried out at $823-1023 \mathrm{~K}$ during 30 min under $\mathrm{N}_{2}$ atmosphere [98]. Authors of the work [98] showed that applications of the Ni/Al multilayers and AuSn solder reduce the bonding temperature and improve the joining quality. However, taking into account the long annealing period, the importance of reactive $\mathrm{Ni} / \mathrm{Al}$ foil in this technology is doubtful. Classes of materials and items that can be joined by means of Ni/Al RMNFs also include graphite and carbon-carbon composites [99], TiAl alloys and steel [100], and components of MEMs [101]; it is anticipated that this class will expand. Application of highly exothermic $\mathrm{Pd} / \mathrm{Al}$ system for 3D integration and packaging of microelectronic or micromechanical components represents a new prospective scientific and technological direction $[102,103]$. Study of thermal processes in the zone of heat release between the materials should promote development of this method. The rapid release of energy from reactive multilayer foils can create extreme local temperature gradients near substrate materials, which requires experimental and theoretical study; for example, effect of the initial substrate microstructure on microstructural evolution within the heat-affected zone was evaluated experimentally and numerically in two Sn-Zn alloys [104].

Applications of the Ni/Al RMNFs are not confined to joining purposes. Thus, experimental research of the influence of shock compression on the Ni/Al multilayer thin foil [105] may become the starting point for new applications. It seems that various alternative applications of the reactive nanofoils are expectable in the nearest future. Further development of various engineering applications requires better understanding of reaction mechanisms in RMNFs, which can be achieved by molecular dynamics simulations used together with new experimental approaches.

\section{Molecular dynamics study of the reactivity of Ni/Al systems}


The molecular dynamics method permits investigation of a large variety of physical properties of systems such as solid and liquid Ni-Al alloys, pure Ni and pure Al metals, B2-NiAl and $\mathrm{Ni}_{3} \mathrm{Al}$ intermetallic compounds, etc. The size-effects related to nanosystems have also been considered. A brief overview of the MD simulations of the $\mathrm{Ni}-\mathrm{Al}$ bulk system and nanosystems is reported in this section. Three main groups of nanosystems are considered: nanoparticles, nanowires and nanometric metallic multilayers. We have put aside a large set of works which are not directly related to the reactive aspects of nano-NiAl-systems (i.e. dislocations, mechanical behavior, ...).

\subsection{Bulk systems}

Bulk properties of the Ni-Al system have been extracted from MD simulations by setting up periodic boundary conditions. We here report some examples.

Using a two-phase method, the melting temperatures were obtained for pure $\mathrm{Ni}$ and $\mathrm{Al}$ [106,107] metals, and for the B2-NiAl [108] and $\mathrm{Ni}_{3} \mathrm{Al}$ [109] intermetallic compounds. The two-phase method is based on a simulation in which solid and liquid phases coexist, as shown in Fig. 10 for the case of adiabatic conditions (NVE conditions). In NVE simulations, the temperature $\mathrm{T}$ and pressure $\mathrm{P}$ are measured for each system. Extrapolation of $\mathrm{T}$ at zero pressure gives the melting temperature of the material. Otherwise, when simulations are performed in the NVT ensemble, the system will reach a single phase. Above the melting temperature $T_{m}$, the system will become liquid whereas below $T_{m}$, a solid phase will appear and grow. The velocity of the solid/liquid interface depends on the system temperature. The extrapolation of the interface velocity to zero velocity also gives the melting temperature of the system. This approach have been used by Turlo et al. [55] in order to obtain the melting temperatures of the pure $\mathrm{Ni}$ and $\mathrm{Al}$, and of the $\mathrm{NiAl}$ and $\mathrm{Ni}_{3} \mathrm{Al}$ intermetallic phases for three different interatomic potentials. 
The diffusion mechanisms in $\mathrm{B} 2-\mathrm{NiAl}$ were evaluated by Mishin et al. [110] for the case of Ni vacancy jumps in the intermetallic compound. They showed that the atomic configuration after one $\mathrm{Ni}$ vacancy jump is unstable and involves additional collective jumps. In the majority of $\{110\}$ six-jump vacancy cycles, an Ni vacancy was observed. This type of diffusion is a standard mechanism, reported since 1958. However, new mechanisms involving ten- and fourteen-jump cycles of the $\mathrm{Ni}$ and $\mathrm{Al}$ vacancies were also observed by Soule De Bas and Farkas [111].

Several phase transformation processes in the $\mathrm{Ni}-\mathrm{Al}$ system, such as melting and crystallization of $B 2-\mathrm{NiAl}[112,113]$ have been investigated by using the MD method. Ovrutsky and Prokhoda [114] studied the B2-NiAl phase nucleation in an undercooled equiatomic Ni-Al melt. In such systems, the $B 2-\mathrm{NiAl}$ phase starts to crystallize at $900 \mathrm{~K}$, well below the melting temperature of the intermetallic phase. In the temperature range $[1500 \mathrm{~K}$ $950 \mathrm{~K}]$, the dependence of the critical nucleus size on the undercooling (larger size for lower supercooling) was evaluated. These authors also observed an increase in the growth velocity in the case of extreme undercooling, due to the retardation of diffusion kinetics in these conditions.

The ordering process of the equiatomic Ni-Al binary alloy at various temperatures below the melting point of the B2-NiAl intermetallic compound was studied by Kuhn and Horbach [115]. An inhomogeneous system with planar crystal-melt interfaces in (100) orientation was prepared and simulated. The formation of a high nonequilibrium concentration of point defects was observed. A detailed study of defect generation during crystallization of the B2ordered NiAl compound was performed by Zheng et al. [116] for the (100), (110), and (111) growth directions. Disorder and defect trapping upon rapid solidification was observed. The analysis of the crystallized $B 2-\mathrm{NiAl}$ phase shows that vacancies are located primarily on the 
Ni sublattice and the antisite defects are mainly Ni atoms on the Al. It was also found that the interface orientation has no influence on the concentration of the defects.

Turlo et al. [55] performed a systematic investigation of the different bulk properties, such as lattice parameter, enthalpy, mass diffusivity, thermal conductivity, etc., for three different interatomic potentials. They have compared an extracted MD data with available experimental data and determined the limitations of the EAM potentials for studying different aspects of reactivity in the Ni/Al RMNFs. A key feature is the thermal conductivity, which differs from experimental values by one order of magnitude. It might seem a major disadvantage because heat transfer governs the self-sustained propagation of the reactive process. The direct comparison of MD results with experimental measurements seems impossible. In fact, it is a serious advantage in order to investigate the reactive wave propagation in the framework of MD simulations. To do so, the length of the sample in the direction of the reactive front propagation has to be larger than that in the conduction zone (see for example [1,64]). In experiments, the thickness of the conduction zone is around 2-10 $\mu \mathrm{m}$ [117]. This length-scale is hard to reach in MD simulations and requires a lot of computational power. In fact, the low value of the thermal conductivity gives an artificially reduced conduction zone. This limitation has enabled the design of large scale MD simulations in order to study the elemental mechanisms and the phase transformations that occur during reactive wave propagation $[30,118,119]$. Here, the limitations of some aspects extended the possibility of studying other aspects of the physical phenomena.

\subsection{Nanosystems}

Four main types of $\mathrm{Ni}-\mathrm{Al}$ nanosystems with different geometries have been studied by means of molecular dynamics simulations: nanoparticles (spherical geometry), nanowires (cylindrical geometry), nanofilms and nanometric multilayers (both with a planar geometry).

\subsubsection{Nanoparticles (NP)}


$\mathrm{Ni}-\mathrm{Al}$ nanoparticles (NP) are formed by homogeneous or heterogeneous atomic clusters with a size of several nanometers $(1-100 \mathrm{~nm})$. They exhibit very specific properties compared to bulk systems.

Delogu investigated the melting behavior of solid Al, Ni and NiAl nanoparticles $(1-10 \mathrm{~nm})$ [120]. He observed a strong depression of the melting point in those systems. This is particularly striking for NiAl NPs of $4 \mathrm{~nm}$, which melt at a temperature below Ni NPs of the same size. This leads to the demixing of $\mathrm{Ni}$ (into the core) and $\mathrm{Al}$ (into the shell) species in NiAl molten particles.

Homogeneous nanoparticles are not the only systems to have been widely investigated using MD simulations. Heterogeneous systems, such as a metal nanoparticle coated with another metal (core-shell systems), have also been studied. Song and Wen [121] investigated the heating and cooling of a nickel-coated aluminum nanoparticle with a $\mathrm{Al}$ core of $4 \mathrm{~nm}$ in diameter and an $\mathrm{Ni}$ shell of $0.5 \mathrm{~nm}$ thick. They observed a two-way diffusion of both aluminum and nickel atoms, the glass phase formation for a fast cooling rate, and $L l 2-\mathrm{Ni}_{3} \mathrm{Al}$ phase formation associated with the segregation of $\mathrm{Al}$ atoms under a low cooling rate. They also found that the presence of the $\mathrm{Ni}$ shell increased the melting point of the $\mathrm{Al}$ core by approximately $200 \mathrm{~K}$.

The thermochemical behavior associated with alloying and reactivity of nickel-coated aluminum [122,123,124] and aluminum-coated nickel [125,126,127] nanoparticles have also been well investigated. Sundaram et al. [125] determined the diffusion coefficient of Ni atoms in the $\mathrm{Al}$ shell as a function of the temperature and shell thickness. They found that the reaction rate is controlled by the diffusion of Ni into liquid Al. Evteev et al. [123] observed two stages in the reaction: alloying and the formation of $B 2-\mathrm{NiAl}$, for which the adiabatic temperature is close to the melting temperature of a $\mathrm{B} 2-\mathrm{NiAl}$ ordered structure. 
Henz et al. [128] studied Ni-Al coated nanoparticles as a model for nanoparticles embedded within a matrix. Moreover, they also considered the kinetic sintering of separate $\mathrm{Ni}$ and $\mathrm{Al}$ nanoparticles as a model system for powder metallurgy [129]. Two stages of the sintering process were identified: (1) Al atoms are attracted to the Ni surface particle due to surface energy minimization. Ni-Al bonds are formed. (2) Melted alloy is formed. Henz et al. also reported on the effects of nanoparticle size on sintering temperature and characteristic time. The reaction time increases and the adiabatic temperature decreases as the size of the nanoparticles increases. These authors also found a slight effect of surface energy on the combustion temperature for particles with a diameter of less than $10 \mathrm{~nm}$.

\subsubsection{Nanowires}

Cherukara et al. [130] studied the reaction mechanisms in thermally ignited reactive samples of core/shell $\mathrm{Ni} / \mathrm{Al}$ wires. Samples ignited at low and at high temperatures follow very different reaction paths. Solid-phase diffusion and formation of the B2-NiAl phase in samples ignited at low temperatures (900 K or less) were observed. For higher ignition temperatures, an accelerated diffusion of Ni into molten Al leads to a completely molten final state. The microstuctural evolution of $\mathrm{Ni} / \mathrm{Al}$ nanowires was clearly identified for different ignition temperatures.

\subsubsection{Nanofilms}

Molecular dynamics simulations were also used to explore the microscopic properties of nanofilms of $\mathrm{Ni}, \mathrm{Al}$ and B2-NiAl. Surface segregation and diffusion in a (110) B2-NiAl thin film were studied by Levchenko et al. [131] and by Evteev et al. [132,133]. The simulations were performed at a temperature just below the melting temperature the $B 2-\mathrm{NiAl}$ bulk phase. The (110) surface was observed to be relatively stable, but developed adatoms, vacancies and antisites. Almost all adatoms were Al atoms. The first (surface) and second (subsurface) layers of the (110) surface were more enriched in $\mathrm{Ni}$ (51\% of $\mathrm{Ni}$ atoms) as compared to the 
bulk composition. The main diffusion mechanism was determined to be six-jump cycles of a $\mathrm{Ni}$ vacancy. In addition, the $\mathrm{Ni}$ atoms were found to diffuse more than 2 times faster than the $\mathrm{Al}$ atoms.

The atom-by-atom deposition of one metal on the substrate of another metal was investigated for the $\mathrm{Ni}-\mathrm{Al}$ system. The deposition of $\mathrm{Ni}$ atoms on an $\mathrm{Al}(100)$ surface was investigated by Lee et al. [134]. They observed the intermixing process between $\mathrm{Ni}$ and $\mathrm{Al}$ at the interface, followed by the formation of the $B 2-\mathrm{NiAl}$ and $\mathrm{L} 12-\mathrm{Ni}_{3} \mathrm{Al}$ intermetallic compounds, when the adatom incident energy is low $(0.1 \mathrm{eV})$. In general, it was found that the interface structure is strongly dependent on the temperature of the substrate and the incident energy of an adatom. Lee and Chung studied the deposition of (1) $\mathrm{Ni}$ atoms on $\mathrm{Al}(100), \mathrm{Al}(011)$ and $\mathrm{Al}(111)$ surfaces [135]; (2) Al atoms on an $\mathrm{Ni}(001)$ surface [136]; and (3) $\mathrm{Ni}$ and $\mathrm{Al}$ atoms on an $\mathrm{Ni}(111)$ surface [137]. The highest surface roughness was found in the case of the $\mathrm{Al}(111)$ surface. In the case of deposition of the $\mathrm{Ni}$ and $\mathrm{Al}$ atoms on a $\mathrm{Ni}$ (111) surface, the $\mathrm{Al}$ thin film grew in a layer-by-layer mode, whereas the deposited $\mathrm{Ni}$ atoms tended to build an island structure at the surface. Thin $\mathrm{Al}$ film growth and interface structure during aluminum deposition on $\mathrm{Ni}(100)$ substrate were also investigated by Hassani et al. [138]. In most cases, they observed a layer-by-layer mode for the Al film growth with preferable fourfold geometry.

\subsubsection{Nanometric multilayers}

Different aspects of nanometric multilayers have been extensively studied by many groups over the past decades. Zhao et al. [139] studied a shock propagation in Ni/Al nanolaminates. A highly exothermic chemical reaction was observed when the nanolaminates were shocked in the normal direction to the $\mathrm{Ni} / \mathrm{Al}$ interface.

The reactivity, the microstructure transformations and the transport properties of $\mathrm{Ni} / \mathrm{Al}$ multilayered systems have also been investigated by Baras and Politano [140]. The system 
was initially heated at $600 \mathrm{~K}$. At this temperature, the exothermic reaction began with a large release of heat and an increase in the system temperature. These authors also found that the reaction in the $\mathrm{Ni} / \mathrm{Al}$ reactive multilayers is controlled by the mutual solid-state diffusion of 39] the $\mathrm{Ni}$ and $\mathrm{Al}$ atoms across the interface, followed by the formation of the $\mathrm{B} 2-\mathrm{NiAl}$ intermetallic phase. That finding is consistent with the results of Cherukara et al. [141] and with those of Izvenkov and Rice [142].

Crone et al. [143] examined the role of microstructure in the initiation of $\mathrm{Ni} / \mathrm{Al}$ reactive multilayers. The MD results show that the reaction ignition temperature drops significantly with the increasing misfit strain. Weingarten et al. [144,145] investigated the influence of pressure on the rates of atomic mixing and alloying reactions. They found that the pressuredependent melting behavior of $\mathrm{Ni}$ and $\mathrm{Al}$ layers plays a significant role in the mass transport and the exothermic reaction rate in the $\mathrm{Ni} / \mathrm{Al}$ multilayers.

The features of atomic diffusion in Ni/Al nanolaminates were studied by Rizzi et al. [146] and by $\mathrm{Xu}$ et al. [147] for a wide range of temperatures. The intermixing of the Ni-Al layers was found to be the main process at high temperatures. Two stages were observed at intermediate temperatures: dissolution of the $\mathrm{Ni}$ into liquid $\mathrm{Al}$ with the subsequent $\mathrm{B} 2 \mathrm{-NiAl}$ phase formation. At low temperatures, the formation of $\mathrm{B} 2 \mathrm{-NiAl}$ in the beginning of the reaction precludes both of these mechanisms (intermixing and dissolution).

\section{Atomic-scale modeling versus experiments}

In this section, we review our molecular dynamics studies [74,117,148]. We show how atomic-scale modeling provides a useful tool in order to explain the experimental observations obtained with the methods of analysis presented in Sec. 2.2. We first consider the progress of the reaction, phase transformations, and corresponding reactive mechanism. This can be considered as the counterpart of the quenched front analysis. Next, we give the results obtained by the atomic approach of the alloying propagation in nanometric $\mathrm{Ni} / \mathrm{Al}$ 
multilayers. This analysis provides a modeling of the experiments on the reactive wave propagation in free-standing foils.

\subsection{Phase transformations}

The question of phase transformations in self-propagating reactive wave is of primary interest for understanding the reaction mechanisms. To handle this problem in the framework of MDS, the atomic and microstructure evolution was simulated at a fixed temperature. A representative temperature was chosen close to the melting point of $\mathrm{Al}$. A layered $\mathrm{Ni}(\mathrm{s})-\mathrm{Al}(\mathrm{s})-$ $\mathrm{Ni}(\mathrm{s})$ system was designed in order to mimic the experimental system, where $\mathrm{s}$ is solid (see section 4.2). The evolution of the system was followed with the different indicators presented in Sec. 3.3. Figures 11 show snapshots of the system and corresponding number density profiles, at different times.

The MDS reveal the basics mechanisms that underlie the processes. The following steps were identified:

(1) In a very short time, the inner layer becomes partially disordered while line defects appear in the remaining solid. This leads to complete melting of the Al layer with no more clear evidence of atomic planes in the inner layer. During the wetting of the $\mathrm{Ni}$ surfaces by $\mathrm{Al}$ atoms, the $\mathrm{Ni}$ atoms close to the interfaces leave the substrate and move into the inner layer. The number of $\mathrm{Ni}$ atoms in the inner layer increases. (Fig. 11a-b)

(2) The migration of $\mathrm{Ni}$ atoms promotes the formation of vacancies that are progressively occupied by $\mathrm{Al}$ atoms. These $\mathrm{Al}$ atoms remain located close to the interface because of the slow diffusion rate in the solid phase. There exist well-defined atomic planes of $\mathrm{Al}$ and $\mathrm{Ni}$ in the close vicinity of the interface. A local reorganization of $\mathrm{Al}$ and $\mathrm{Ni}$ atoms leads to the formation of seeds of a bcc-like new phase as shown by the bcc-peak observed around the interface. The sharp interface between solid $\mathrm{Ni}$ and solid Al, 
becomes a diffuse interface between solid $\mathrm{Ni}$ and liquid layer $(\mathrm{Ni}+\mathrm{Al})(\mathrm{m})$ with an interlayer of solid solution $(\mathrm{Ni}+\mathrm{Al})(\mathrm{ss})$, where $\mathrm{m}$ is melted and $\mathrm{ss}$ is solid solution.

(3) An intensive diffusional flux of $\mathrm{Ni}$ atoms into the inner layer is observed. The whole surface of the Ni layers acts as a continuous source of $\mathrm{Ni}$ atoms to feed the inner layer, until a saturation limit is reached [29]. Diffusion of $\mathrm{Ni}$ is the key process of intermixing between $\mathrm{Ni}$ and $\mathrm{Al}$ atoms.

(4) During the diffusion-limited dissolution of $\mathrm{Ni}$ in $\mathrm{Al}$, a phase transformation starts to develop at the interface leading to the formation of $\mathrm{B} 2 \mathrm{-NiAl}$ intermetallic compound. The atomic arrangement of $\mathrm{B} 2-\mathrm{NiAl}$ is characteristic of a (110) orientation. In fact, there exist epitaxy relations between the fcc-Ni and the bcc-NiAl that allow the formation of $B 2-\mathrm{NiAl}$ at the interface [149]. The number of allowed orientations is limited and depends on the orientation of the Ni interface. On the other hand, the formation of $B 2-\mathrm{NiAl}$ is favored by a $50 / 50$ local composition. After nucleation, the first plane close to the interface starts to be filled by $B 2-\mathrm{NiAl}$ unit cells but upper planes start to be arranged in bcc orientation before the bcc coverage of the lower plane is completed. This results in rounded grains of different orientations. (see Fig. 11c-f). The solid B2-NiAl does not form a continuous layer: about $20 \%$ of a disordered phase remain between the solid grains. Liquid inter-grains layers persist due to the different crystal orientations of the intermetallic grains which prevent a coherent joining of the neighboring crystals. Note that the operating temperature $T$ plays a crucial role in the microstructure observed, as shown in Fig. 12. This is mainly due to a higher solubility for increasing values of $T$. In addition, for higher $T$ values, the phase transformation develops more rapidly and the grains size becomes larger. 
(5) As the solid-state diffusional flux of $\mathrm{Ni}$ atoms through the NiAl phase is negligible, the growth of the intermetallic grains is only due to precipitation of $\mathrm{Ni}$ already in the melt. Thus, the $\mathrm{Ni}$ atoms that arrived in the molten $\mathrm{Al}$ layer through the liquid channels between solid grains restore the solubility and, sooner or later, precipitate on the growing facets of the NiAl grains. See Fig. 13.

The resulting microstructure consists of NiAl hanging on to the interfaces, as shown in Fig. 11 and 12. The underlying mechanism was found to be a succession of transformations: amorphization or melting of the aluminum layer, partial dissolution of nickel into liquid aluminum, and formation of intermetallics:

$$
\mathrm{Ni}(s)+\mathrm{Al}(s) \rightarrow \mathrm{Ni}(s)+\mathrm{Al}(m) \rightarrow \mathrm{Ni}(s)+\operatorname{AlNi}_{\mathrm{x}}(m) \rightarrow \mathrm{Ni}(s)+\operatorname{AlNi}_{\mathrm{x}}(m)+\mathrm{NiAl}(s)
$$

The round shaped solid grains of $\mathrm{NiAl}$ phase, if present, do not form a continuous interface layer at the $\mathrm{Ni} / \mathrm{Al}$ boundary, but exhibit different crystallographic orientations, and remain separated by liquid/amorphous interlayers.

In the case of a layered $\mathrm{Ni}(\mathrm{s})-\mathrm{Al}(\mathrm{m})-\mathrm{Ni}(\mathrm{s})$ prepared at a temperature higher than the melting temperature of $\mathrm{Al}, T>T_{m}(\mathrm{Al})$, the problem of the reactive dissolution of $\mathrm{Ni}$ in the liquid layer was systematically studied by means of MDS in [29]. The time evolution of the fraction of $\mathrm{Ni}$ atoms in the liquid slice was fitted by the solution of a dissolution rate equation derived in the case of a diffusion-limited dissolution (see [29] for more details). The model is tractable enough to use the simulation data to extract kinetic parameters such the diffusion coefficient. If the diffusion is assumed to follow the Arrhenius relationship:

$$
D=D_{0} \exp [-E / R T]
$$

where $Q$ is the activation energy and $D_{0}$ is the prefactor, we get $E=43.7 \mathrm{~kJ} \mathrm{~mol}^{-1}$ and $D_{0}=6.57$ $10^{-7} \mathrm{~m}^{2} / \mathrm{s}$ that correlate well with experimental data. A systematic study proves that the solubility limit of $\mathrm{Ni}$ into liquid $\mathrm{Al}$ increases with the temperature and the complete solubility corresponds to the melting temperature of Ni. In a complementary set of simulations (NPH), 
the amount of heat delivered by the mixing between $\mathrm{Ni}$ and $\mathrm{Al}$ was evaluated [30]. In such an adiabatic system, the heat release due to dissolution is only used to heat up the system. The fit to the time evolution of the temperature gives an estimation of the heat of dissolution, as measured in MD simulations: $76 \mathrm{~kJ} \mathrm{~mol}^{-1}$.

\subsection{Self-propagating reaction in $\mathrm{NiAl}$ multilayers nanofoils}

Self-propagating high-temperature reactions that occur in multilayer nanofoils were first studied by means of molecular dynamics simulations by Politano and Baras [118]. The system is composed of two alloyable constituents stacked over a few hundred nanometers. The simulation of a reactive wave at the microscopic level requires a sufficiently large system to allow thermal conductive transport to proceed in at least one direction for a sufficiently long time. Thus the system studied here was about $0.5 \mu \mathrm{m}$ long in the $x$ direction and contained more than 1.5 million atoms. The reaction was initiated locally by increasing the temperature at one edge of the sample, as it is done in experiments. Then the system was kept in adiabatic conditions. A self-sustaining reaction was observed to propagate along the foil. The multilayered $\mathrm{Ni} / \mathrm{Al}$ nanofoils were prepared at different initial temperatures $\left(T_{0}=\right.$ $300 \mathrm{~K}-600 \mathrm{~K}$ ) and various stoichiometry (the mole fraction of $\mathrm{Ni}$ is ranging from 0.35 to 0.7). As in experiments with high speed camera, it is possible to follow the front and determine its main characteristics. The most common way to characterize a front is to determine its velocity. The position of the front is commonly defined by the position of the inflection point on the temperature profile. Stationary reactive wave propagation was observed. In MD simulations, the typical value of the velocity is between $10 \mathrm{~m} / \mathrm{s}$ and $40 \mathrm{~m} / \mathrm{s}$. In fact, MDS represent the system the ideal conditions with absence of initial premixing and heat loss. These factors lead to a decrease of the reactive front velocity that are not taken into account in the modeling. 
In MDS, the influence of parameters such as the initial temperature of the foil or the stoichiometry can be systematically investigated. We here discuss three representative situations. Let us first consider the case of an equiatomic system $(n=0.49)$ at $600 \mathrm{~K}$. The snapshot of the system and the corresponding profiles are presented in Fig. 14. The stationary propagation is driven by the reactive dissolution process alone. The self-sustained propagating reaction mediated only by the exothermic dissolution of $\mathrm{Ni}$ into liquid $\mathrm{Al}$ was studied in detail in the case of an equiatomic system in [30]. We brought to light three main aspects of this system: the heat release due to dissolution is large enough to sustain the propagation; the combustion temperature measured in the MDS corresponds to a thermodynamic estimation and the front velocity depends on the bilayer size as observed experimentally. Along the propagating reactive front (Fig. 14):

- the reaction zone extends from the melting temperature of $\mathrm{Al}$, to the complete dissolution of $\mathrm{Ni}$

- the reaction zone is zigzagged due to the progressive dissolution of $\mathrm{Ni}$ into the liquid $\mathrm{Al}$

- the final product is a solution of $\mathrm{Ni}$ and $\mathrm{Al}$ with a composition equal to $n$

- the conduction zone is the region where the temperature varies from the initial temperature to the melting temperature of $\mathrm{Al}$.

During dissolution, temperature increases and reaches a plateau, corresponding to the combustion temperature $T_{c}$, as shown in the temperature profile of Fig. 14. On the other hand, the combustion temperature can be estimated on the basis of the enthalpy conservation. For the equiatomic $\mathrm{Ni}-\mathrm{Al}$ system, the conservation relation reads

$$
\mathcal{H}\left(T_{0}\right)=0.5 \mathcal{H}_{N i}^{S}\left(T_{0}\right)+0.5 \mathcal{H}_{A l}^{s}\left(T_{0}\right)=\mathcal{H}_{N i+A l}^{m}
$$

The combustion temperature measured during the front propagation and the combustion temperature estimated with the enthalpy conservation law are in good agreement [30]. 
The front velocity $v$, measured in MD simulations, is plotted as a function of the corresponding combustion temperature $T_{c}$ in Fig. 15a. The Arrhenius-like dependence of the front velocity on the combustion temperature $\ln v \sim 1 / T_{c}$ is often used to fit experimental data. The slope is supposed to be equal $E / 2 R$, from which the effective activation energy can be extracted [150]. The linear dependence shown in Fig. 15a gives an effective activation energy for the processes involved in the propagation of the reactive wave: $E=136 \mathrm{~kJ} / \mathrm{mol}$, which is in good agreement with experimental estimations (from 127.9 to $149.8 \mathrm{~kJ} / \mathrm{mol}$ [71] ) for the SHS process in equiatomic Ni/Al multilayered nanofoils [20].

Let us now consider the case of an equiatomic system prepared at $300 \mathrm{~K}$. The temperature profile and the mole fraction profile are presented in Fig. 16. The reactive front in the sample with an initial temperature of $300 \mathrm{~K}$ is separated into two stages: a first front moves forward and is followed by a second one. We note the existence of two plateaus associated with two characteristic temperatures, $T_{c 1}$ and $T_{c}$. The first plateau is associated with the exothermic dissolution process and the second one to an extra heat release due to the formation of the intermetallic phase $\mathrm{B} 2 \mathrm{-NiAl}$. This specific behavior has been reported in recent experiments $[16,74]$. We observed a slowing down of the propagation and a significant increase in the combustion temperature as compared to the previous situation. The nucleation and growth of the $\mathrm{B} 2-\mathrm{NiAl}$ starts at the edge of the solid $\mathrm{Ni}$ fingers which are surrounded by the liquid Ni-Al alloy, as shown in the inset of Fig. 16. When the nuclei are formed, they detach from the solid Ni fingers that move forward with the dissolution wave. If the grains present the same orientation, they coalesce and invade a zone surrounded by the liquid alloy. Behind the dissolution front, a liquid equiatomic alloy is formed at a temperature below the melting temperature of the intermetallic compound. SHS front thus created condition of undercooling for $B 2-\mathrm{NiAl}$ that promotes its crystallization. The growth is favored in the $x$ direction. This pattern is related to the solidification process. When the temperature of the system locally 
reaches the melting temperature of $B 2-\mathrm{NiAl}$, the grains are in equilibrium with the liquid alloy. But due to the negative temperature gradient in the $x$ direction due to conduction, any protrusion may still grow in this direction. A new type of crystallization, named direct crystallization from the melt, was observed in MDS. Three main exothermic processes were identified:

- Dissolution and mixing that produce $\Delta \mathcal{H}_{1}: 59 \%$ of the total.

- Crystallization of $B 2-\mathrm{NiAl}$ that produces $\Delta \mathcal{H}_{2}: 24 \%$ of the total.

- Coarsening of grains that produces $\Delta \mathcal{H}_{3}: 17 \%$ of the total heat release.

The complete description of this specific propagation regime is reported in [64].

We now consider a system with an excess of $\mathrm{Ni}$ at $T_{0}=500 \mathrm{~K}$. The melting $\mathrm{Al}$ front is followed by the dissolution of $\mathrm{Ni}$ and the formation of the $\mathrm{B2}-\mathrm{NiAl}$ phase from the liquid alloy between the solid Ni layers, as shown in Fig. 17. The B2-NiAl grains hanging on to the interface look similar to the ones obtained by the mosaic-dissolution-precipitation mechanism described in Sec. 6.1 (see white zones in the snapshot of Fig. 17). These grains grew and filled the space between the solid Ni layers: $(\mathrm{NiAl})(\mathrm{m}) \rightarrow B 2-\mathrm{NiAl}$. This process was followed by the bending of the solid Ni layers. We observed a very broad reaction zone. Dissolution, nucleation and growth take place at the same time. The reaction zone involves different regions: $(\mathrm{Ni}+\mathrm{Al})(\mathrm{m}) / \mathrm{Ni}(\mathrm{s})$ and $(\mathrm{Ni}+\mathrm{Al})(\mathrm{m}) / \mathrm{B} 2-\mathrm{NiAl} / \mathrm{Ni}(\mathrm{s})$. The combustion temperature is lower than in the previous cases and the propagation velocity too. It happens that the precipitation of the grains in the reaction zone prevents the dissolution of $\mathrm{Ni}$ at the solid/liquid interfaces and slows down the front propagation by reducing the heat release by dissolution. With an excess of $\mathrm{Ni}$, we note a change of regime from pure dissolution to mosaic-dissolution-precipitation of B2-NiAl.

The initial conditions play a important role both in the evolution of the microstructure and SHS features as shown in [64]. 
1. In most situations, the propagation is driven by exothermic dissolution and intermixing. The formation of $B 2-\mathrm{NiAl}$ is observed in the after-burning zone.

2. The formation of $B 2-\mathrm{NiAl}$ by direct crystallization from melt is observed at low initial temperature, in the case of equiatomic system or for a low content of Ni. A two-stage propagation front was observed.

3. For systems, with an excess of $\mathrm{Ni}$, the microstructure is quite different. The rounded grains are formed by a mosaic-dissolution-precipitation mechanism. The formation of grains prevents further dissolution of $\mathrm{Ni}$ at solid/liquid interface and slows down the front propagation. The formation of the $B 2-\mathrm{NiAl}$ grains at interfaces induces a bending of Ni solid layers.

Three regimes of reactive wave propagation with different microstructure evolutions were obtained by varying of the initial temperature (from 300 to $800 \mathrm{~K}$ ) and stoichiometry (from 0.35 to 0.67 of $\mathrm{Ni}$ mole fraction) in the system. All these observations are summarized in Fig. 18. The samples with an excess of Ni prepared at low temperature showed no propagation of the reactive wave. After ignition, the reaction started with the melting of $\mathrm{Al}$, the exothermic dissolution of $\mathrm{Ni}$ into $\mathrm{Al}$ and the formation of $\mathrm{B} 2-\mathrm{NiAl}$ grains. However, the heat delivered by these processes was not sufficient in order to maintain the propagation in a self-sustained way. This case is very similar to the quenched front microstructure observed in experiments [119]. As shown in Fig. 19, the reaction front is divided in four regions: (a) the region of coalescence and coarsening of $\mathrm{B} 2-\mathrm{NiAl}$ grains; (b) the region with nucleation and grain growth of $\mathrm{B} 2-\mathrm{NiAl}$ grains between solid Ni layers; (c) the reactive dissolution zone; (d) the zone of unreacted solid and Al layers.

\section{Conclusions}

The combination of experiments and atomic-scale modeling allowed us to shed a new light on the intrinsic mechanisms of nano-heterogeneous non-isothermal processes and 
structure/phases formation occurring in reactive nanofoils. Molecular dynamics simulations appear as a powerful tool in order to study the reactivity at nanoscale. This approach indeed gives the basic atomic steps leading to the observed microstructure beyond any thermodynamic or kinetic modeling. MDS may be considered as a modeling that offers a counterpart to in-situ experiments to explore elemental mechanisms. In addition, complementary MDS allow us to calculate most of the parameters that are used in numerical modeling at the macroscopic scale. This approach offers a self-consistent multi-scale modeling that provides a powerful tool for the interpretation of experimental results.

Thanks to the common work undertaken by experimentalists and theoreticians, MDS starts to provide a predictive tool to conduct new experiments and avoid useless investigations. Different questions still remain to be addressed such as the diffusion along grain boundaries, the influence of quenching rate on the microstructure, the misorientation of crystal grains, the melting point depression in thin layers, the phase competition at the nanoscale including transient metastables phases and more. Real progress will depend on the reliability of the potential developed in the framework of molecular dynamics. Exothermic reactive waves in various systems such as metal-oxide nanolayers, metallic glasses nanolayers, and amorphous thin films could also be studied by means of atomic scale simulations and compared to experiments.

\section{Acknowledgments}

The use of computational facilities at the Computing Center of the University of Bourgogne, DSI-CCUB, is gratefully acknowledged. We are grateful to Mr. Joshua M. Pauls, Dr. Lars P.H. Jeurgens and Prof. Jolanta Janczak-Rush for helpful discussions. The 
section 4 of this work was done with support of Russian Science Foundation (project no. 16-13-10431).

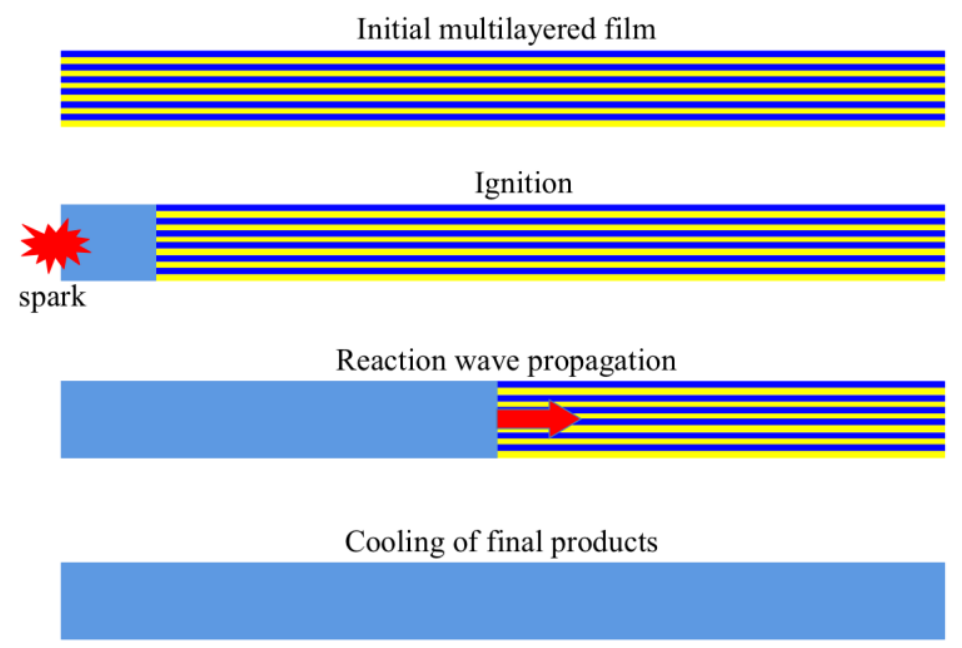

Fig.1 Schematic representation of SHS wave propagation in nanometric metallic multilayers.

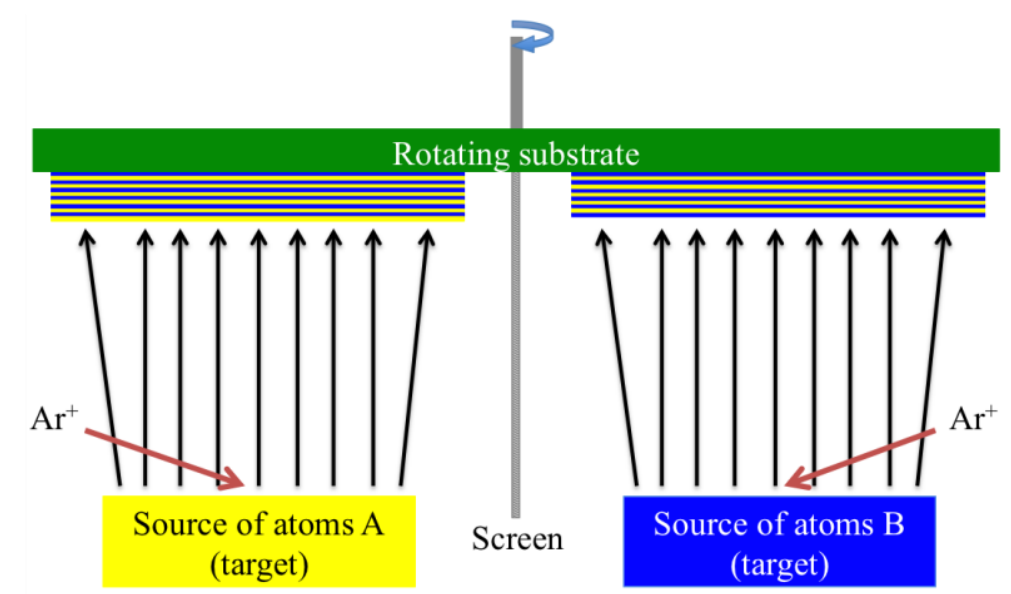

Fig. 2 Schematic representation of the preparation of nanometric metallic multilayers by magnetron sputtering



Fig. 3 Scheme of preparation of nanometric metallic multilayers by the multiple rolling method 
a

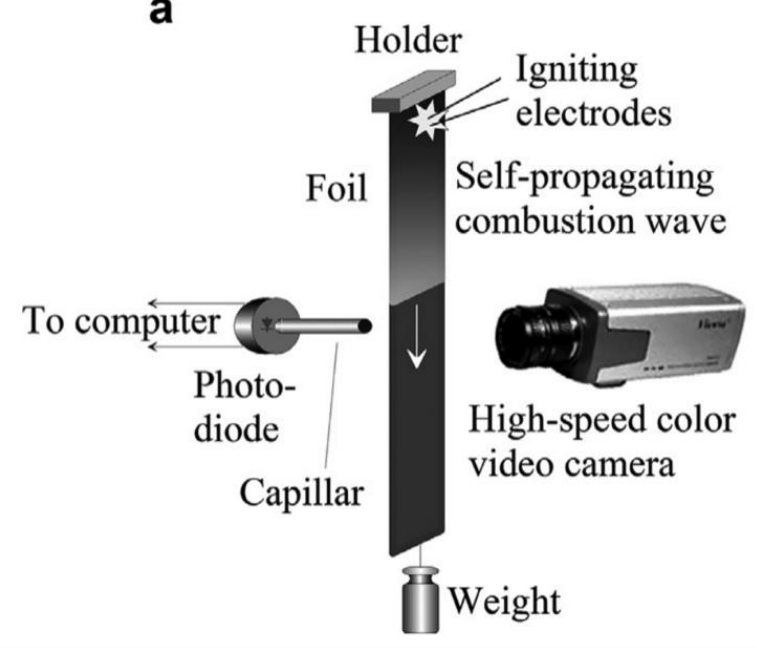

b

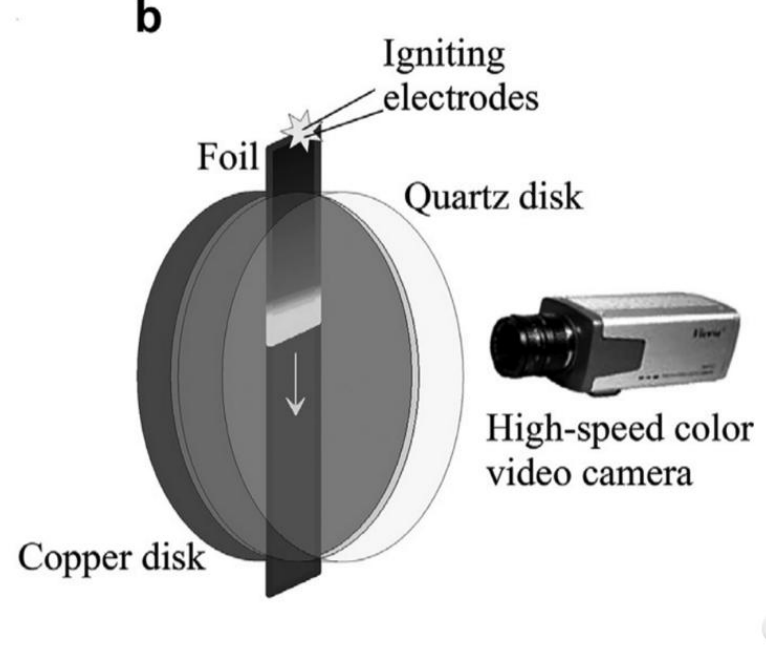

Fig. 4 The experimental schemes used to study SHS in RMNFs. Two kinds of experiments are presented: (a) combustion in a free-standing foil with radiative (low) heat losses; (b) combustion in a foil placed between copper and quartz disks with conductive (high) heat losses. In the last case, the copper disk quenches the reactive front. Reproduced with permission from [74].

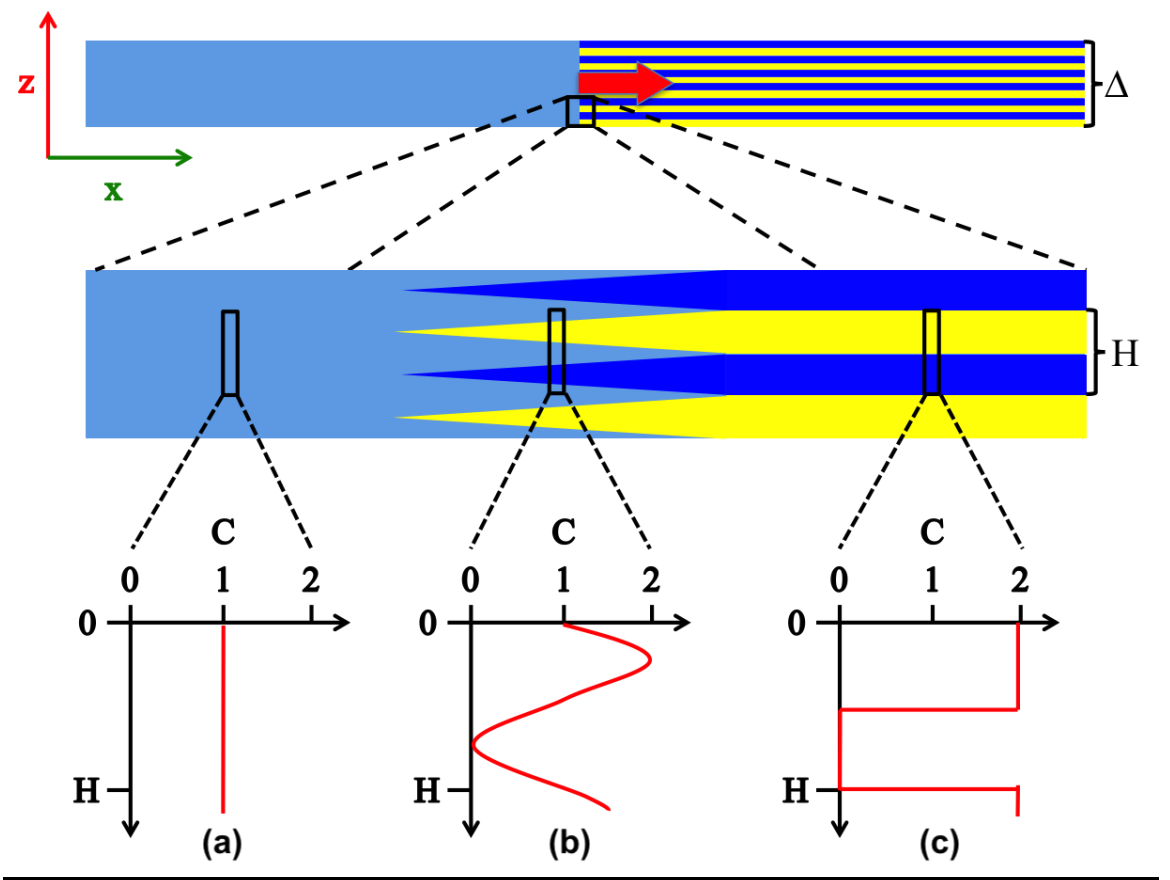

Fig. 5 Scheme of SHS wave propagation modeling in RMNFs. Typical profiles of the concentration $C$ are highlighted by the insets (a) a complete mixing, $(b)$ a smoothed variation in the reaction zone, (c) a step-function for the unreacted layers. 


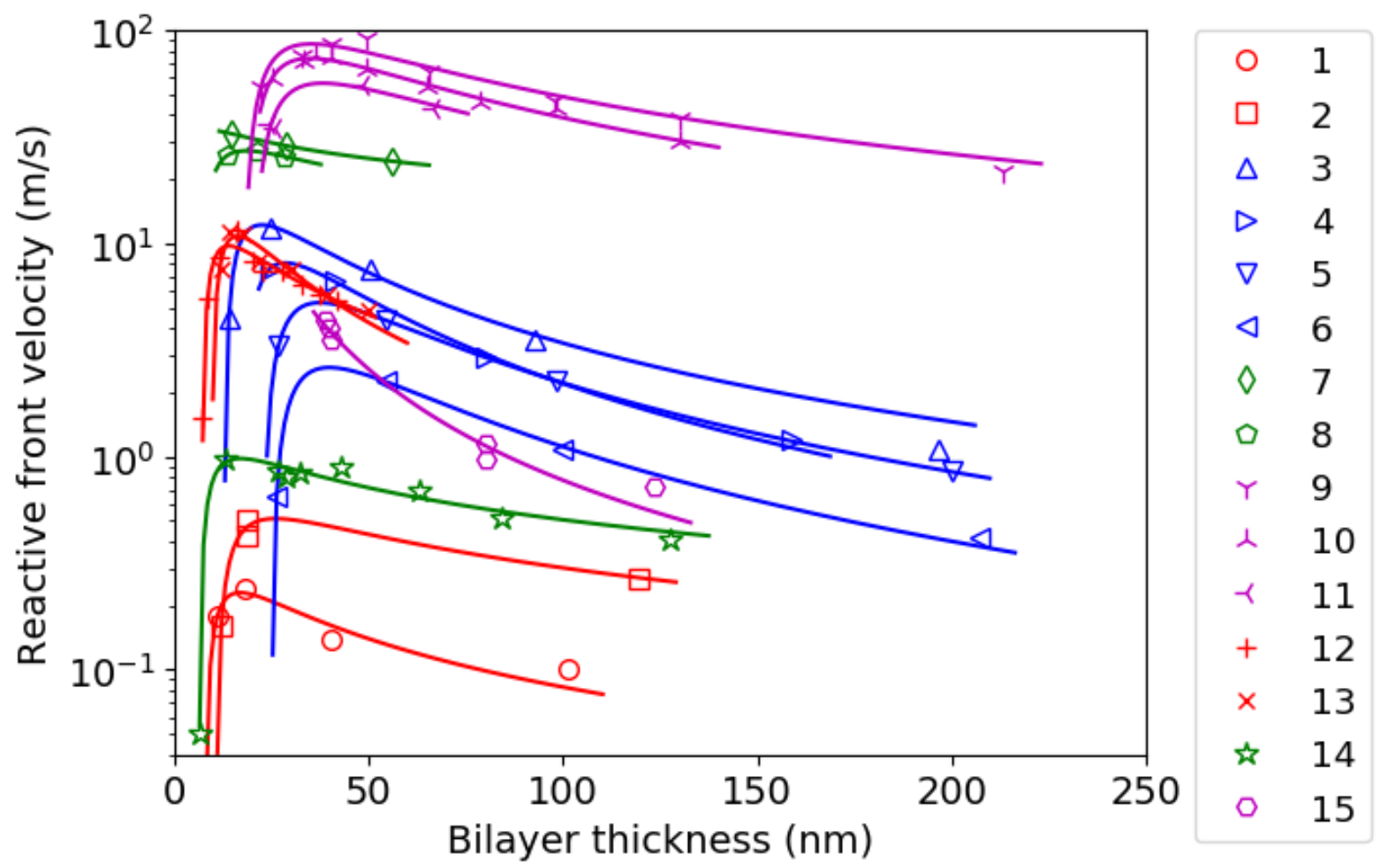

Fig. 6 Plot of the reactive front velocity vs the bilayer thickness for different RMNFs. (1) A Ti/Al film, the initial temperature was $473 \mathrm{~K}$, ignition with a spark [151] (2) ibid, ignition with a heated tungsten filament [151] (3) a Ni/Al film after sputtering, the initial temperature was $298 \mathrm{~K}$ [4] (4) ibid, after annealing at $423 \mathrm{~K}$ for $90 \mathrm{~min}$; [4] (5) ibid, after annealing at $423 \mathrm{~K}$ for $6 \mathrm{~h} \mathrm{[4]} \mathrm{(6)} \mathrm{ibid,} \mathrm{after} \mathrm{annealing} \mathrm{at} 423 \mathrm{~K}$ for $24 \mathrm{~h} \mathrm{[4]} \mathrm{(7)} \mathrm{a} \mathrm{2Ni/Si} \mathrm{film} \mathrm{with} \mathrm{a} \mathrm{total}$ thickness of $1.62 \mathrm{~mm}$, the initial temperature was $298 \mathrm{~K}$ [152] (8) ibid, a total film thickness is $0.73 \mathrm{~mm}$ [152] (9) a Pt/Al film, the initial temperature was $298 \mathrm{~K}$, a total film thickness is $3.6 \mu \mathrm{m}$ [153] (10) ibid, a total film thickness is $1.6 \mu \mathrm{m}$ [153] (11) ibid, a total film thickness is $1.0 \mu \mathrm{m}$ [153] (12) a 2Al/Zr film, the initial temperature was $298 \mathrm{~K}$, a total film thickness was ranged from 25 to $50 \mu \mathrm{m}$ [154] (13) a 3Al/Zr film, the initial temperature was $298 \mathrm{~K}$, a total film thickness was ranged from 25 to $50 \mu \mathrm{m}$ [154] (14) a Ni/Ti film, the initial temperature was $298 \mathrm{~K}$, a total film thickness was $\sim 5 \mathrm{~m}$ [155] (15) a Nb/Si film, the initial temperature was $298 \mathrm{~K}$ [5]. 


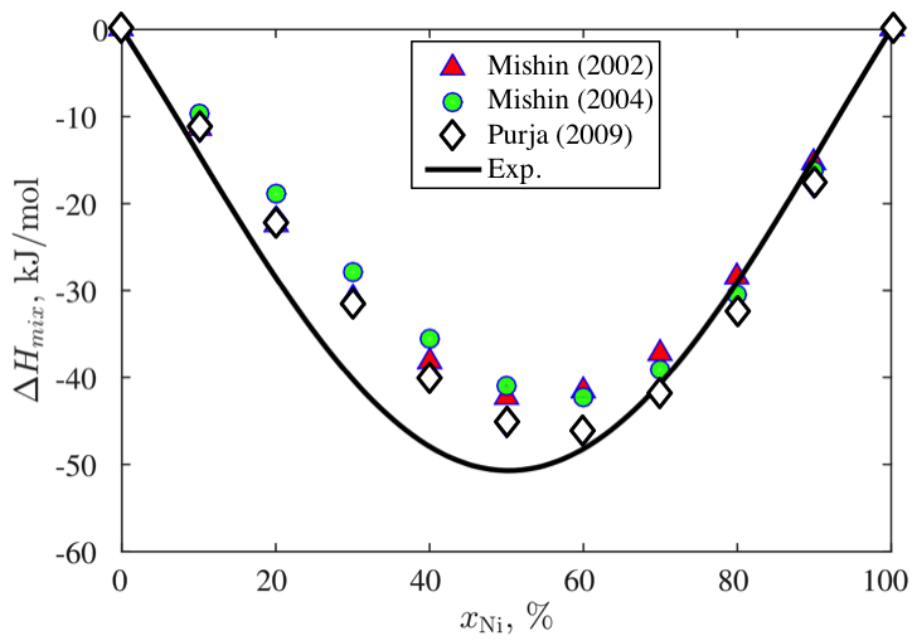

Fig. 7 Mixing enthalpy of the liquid $\mathrm{Ni}-$ Al alloy as a function of Ni composition at $1900 \mathrm{~K}$ computed the interatomic potentials referred as Mishin (2002) [49], Mishin (2004) [53] and Purja (2009) [54]. The black line represents the fit of the experimental values for the temperature range 1700 to $1923 \mathrm{~K}$ [156]

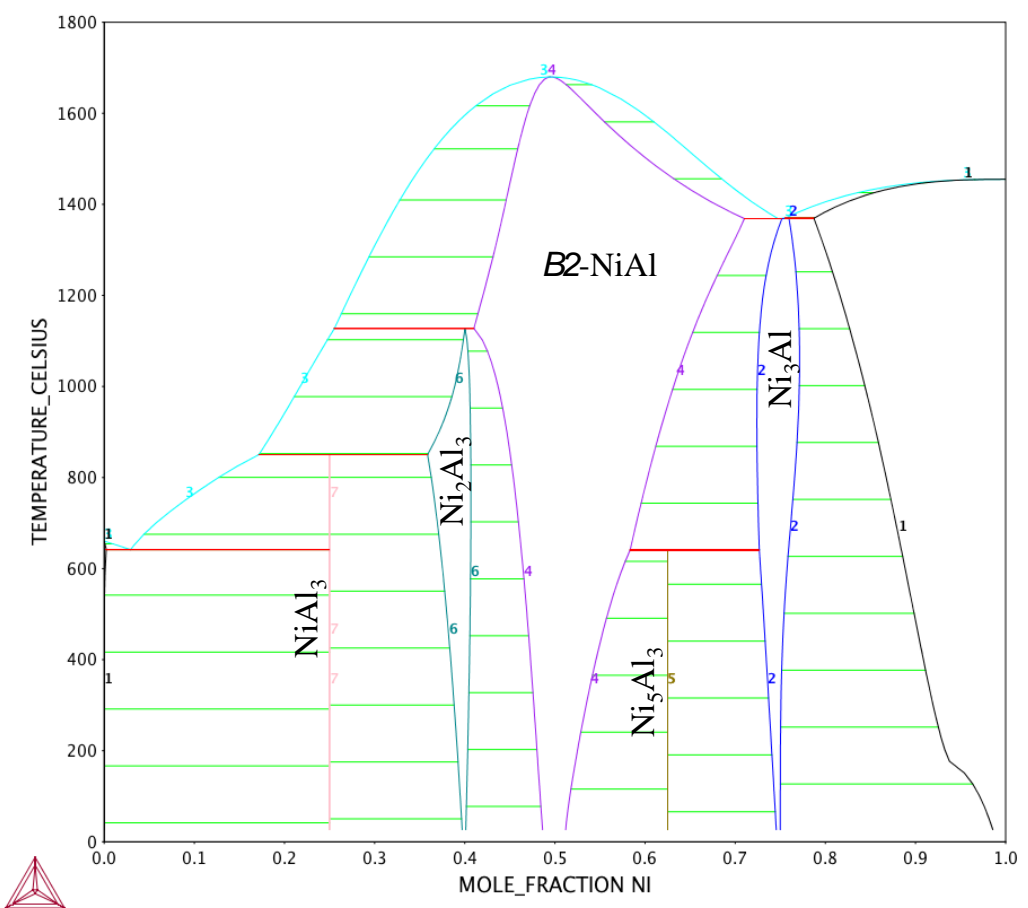

Fig.8 Calculated Nickel-aluminum phase diagram 


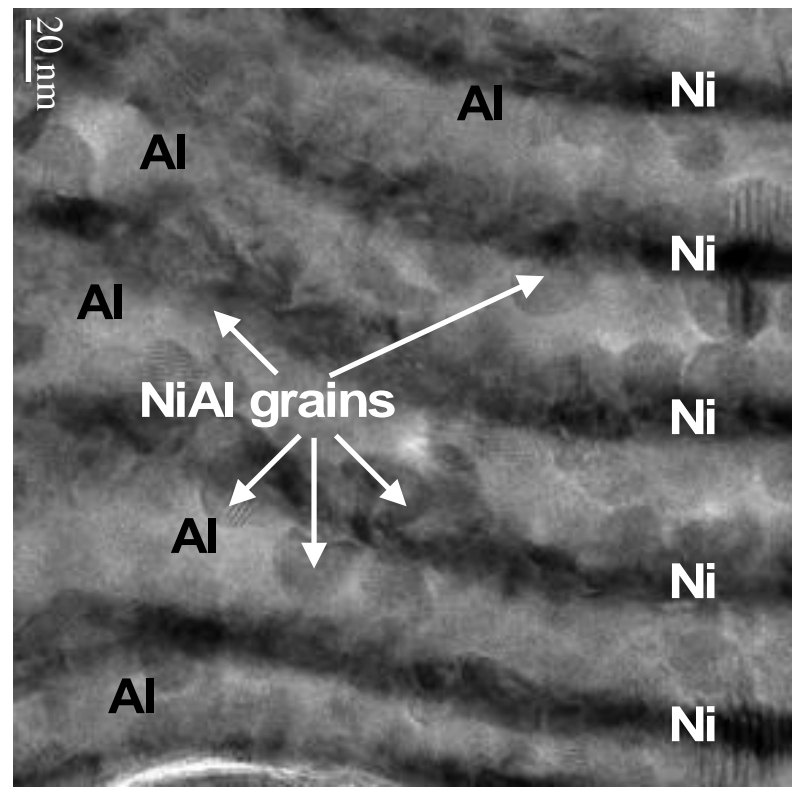

Fig.9 Microstructure of reaction zone of Ni/Al N2M obtained by quenching of reaction wave.

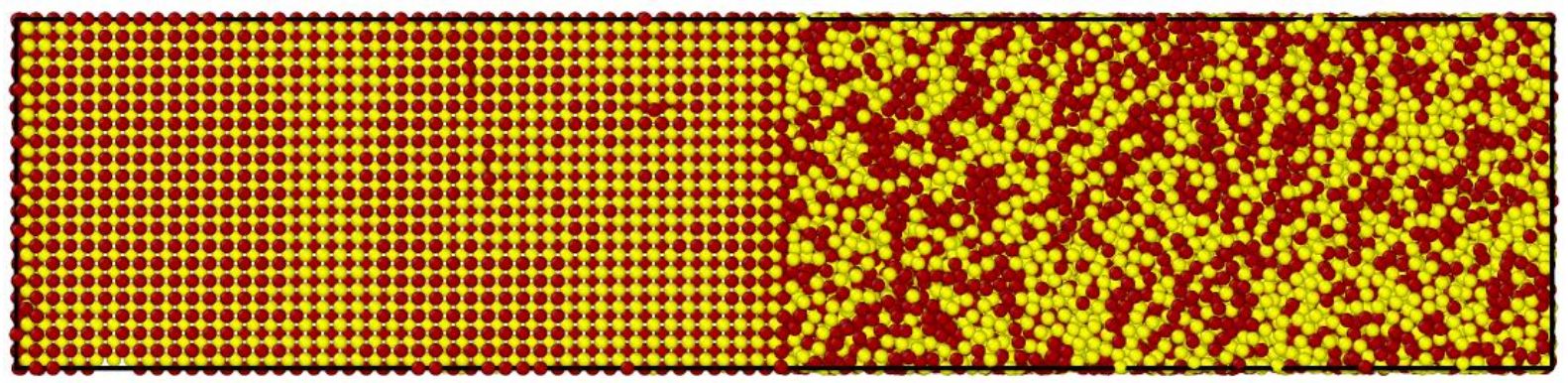

Fig. 10 An example of two-phase system for B2-NiAl intermetallic phase with the (100) solid/liquid interface. Al and Ni are shown as brown (black) and yellow (white) spheres. On the left, the system is crystallized. On the right, the system is an equiatomic Ni+Al melt. 

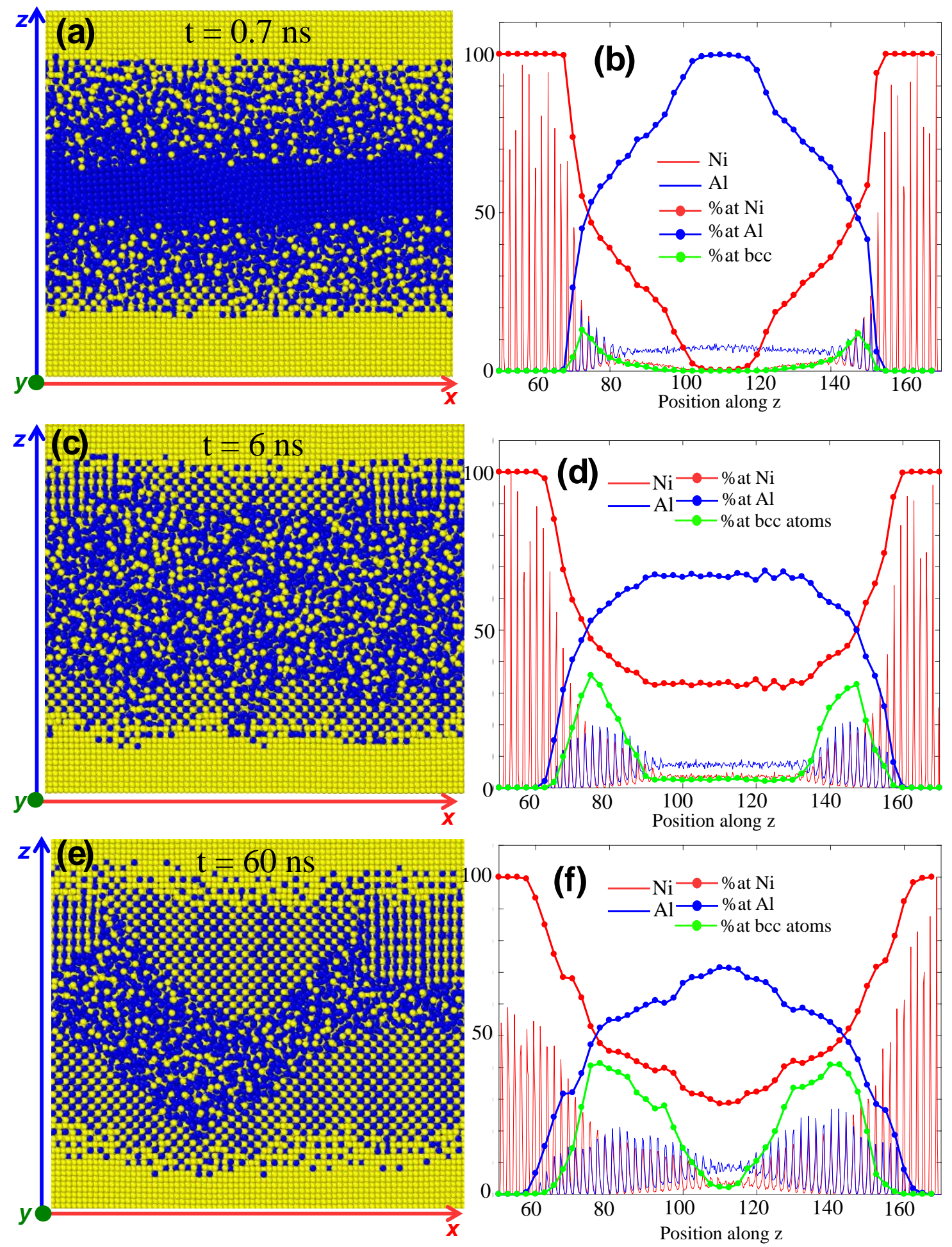

Fig. 11 Snapshots of the Ni-Al-Ni system at $T=1000 \mathrm{~K}$ at different times: $t=0.7 \mathrm{~ns}, t=6 \mathrm{~ns}$ and $t=60 \mathrm{~ns}$. Al and Ni are shown as blue (black) and yellow (grey) spheres. Only the central part of the system is represented. On the right, number density profiles of the Al atoms (thin blue line) and Ni atoms (thin red line), in the zdirection, perpendicular to the interface. For visualization purposes, the scale has been divided by a factor 20. The atomic percentage of $\mathrm{Ni}$, Al and Ni atoms in bcc local configuration within the slices of thickness $0.25 \mathrm{~nm}$ along the z-axis are also shown (lines with bullets). 

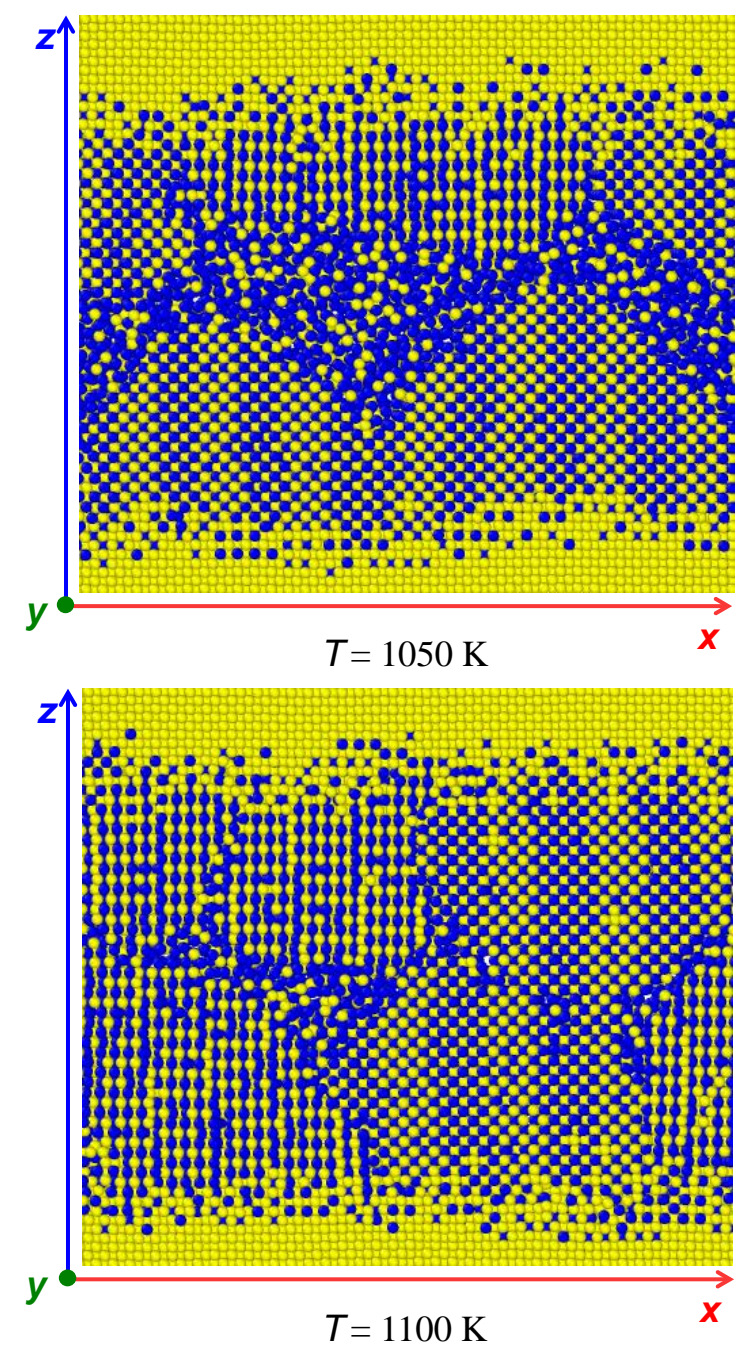

Fig. 12 Snapshots of the Ni-Al-Ni system at $\mathrm{T}=1050 \mathrm{~K}$ and $t=35 \mathrm{~ns}$, and $\mathrm{T}=1100 \mathrm{~K}$ and $t=$ $6 \mathrm{~ns}$. The color-coding allows us to visualize the local arrangement of atoms. Light blue corresponds to bcc atoms and green to fcc atoms. Only the central part of the system is represented. 


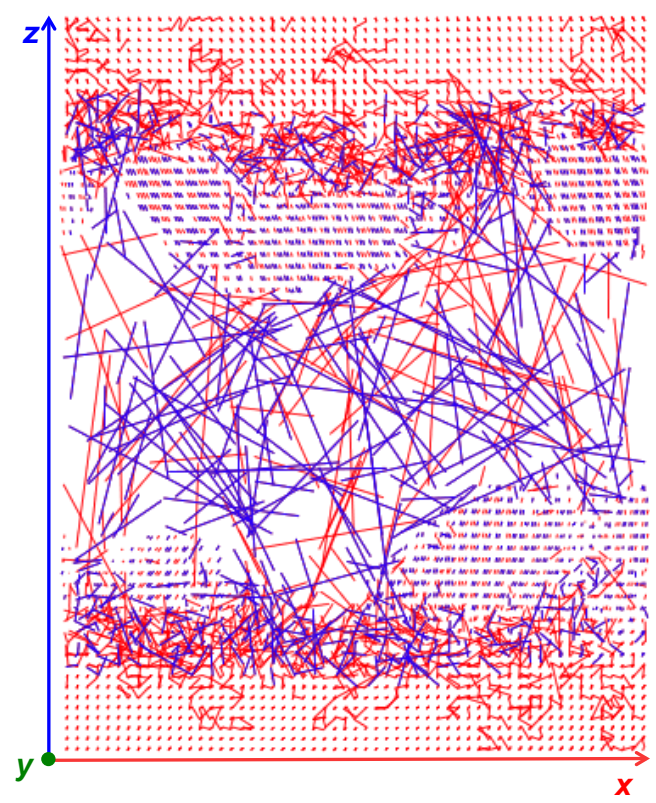

Fig. 13 Snapshot of the reacting layers at $T=1000 \mathrm{~K}$. Displacements of Al (blue) and Ni(red) atoms between 20 and $60 \mathrm{~ns}$ are shown as straight lines. The entire system consists of $39 \mathrm{Al}$ layers and 2 x 40 Ni layers. This corresponds to 316602 atoms. Only a slice in the ydirection of the inner layer is represented to improve visualization.

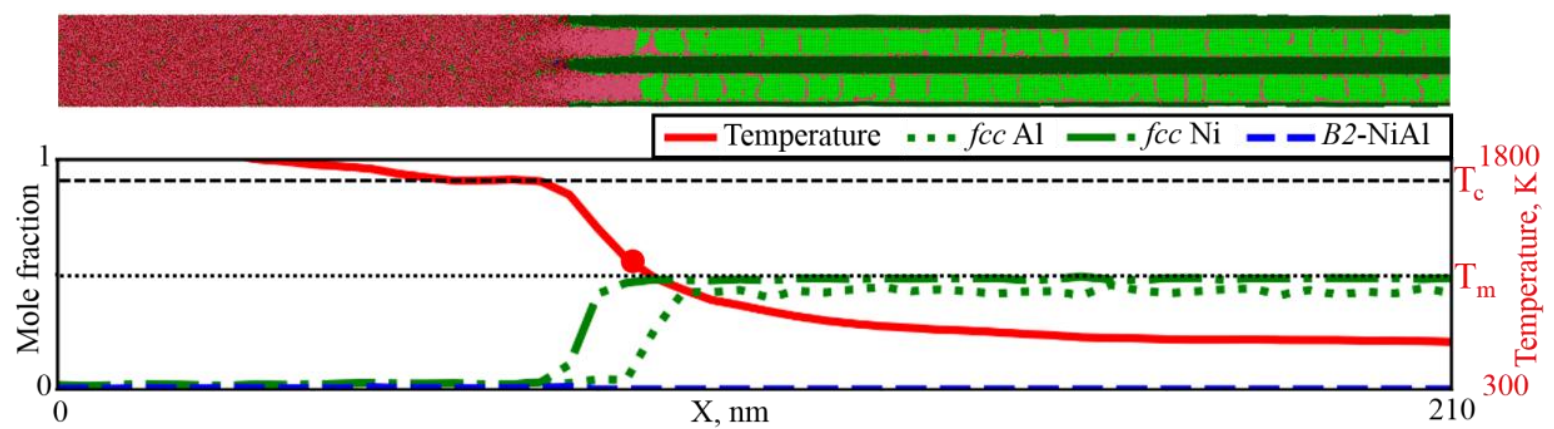

Fig. 14 Snapshot of the equiatomic system with $T_{0}=600 \mathrm{~K}$ at $t=2 n s$. Colors are: redliquid, blue-bcc and green-fcc. Dark atoms are Ni and Light atoms are Al. Profiles of temperature, fcc-Ni and fcc-Al mole fraction at the same time. The dashed lines refer to the melting temperature of $\mathrm{Al}, \mathrm{T}_{m}$, and the temperature of combustion corresponding to the plateau, $T_{c}$. The bullet point denotes the position of the front. 

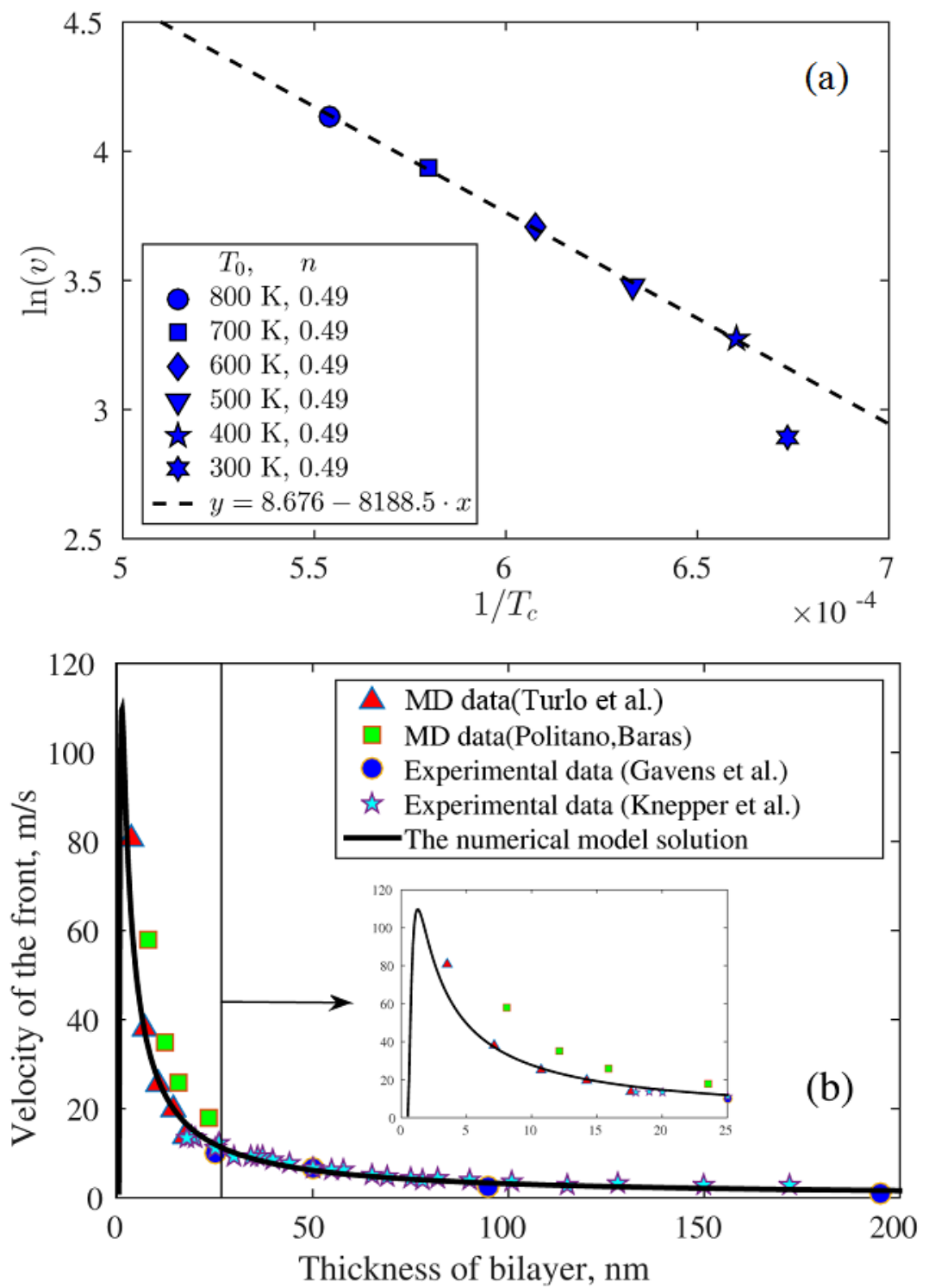

Fig. 15 (a) Arrhenius plot of the front velocity as a function of the inverse of the combustion temperature, $T_{c}$, for a set of equiatomic systems with different initial temperatures. The point at $300 \mathrm{~K}$ is not taken into account for the fit. (b) MD front velocity compared with available experimental [4,69] and MD data [30,118]. The black line represents the approximate solution given in [30]. 


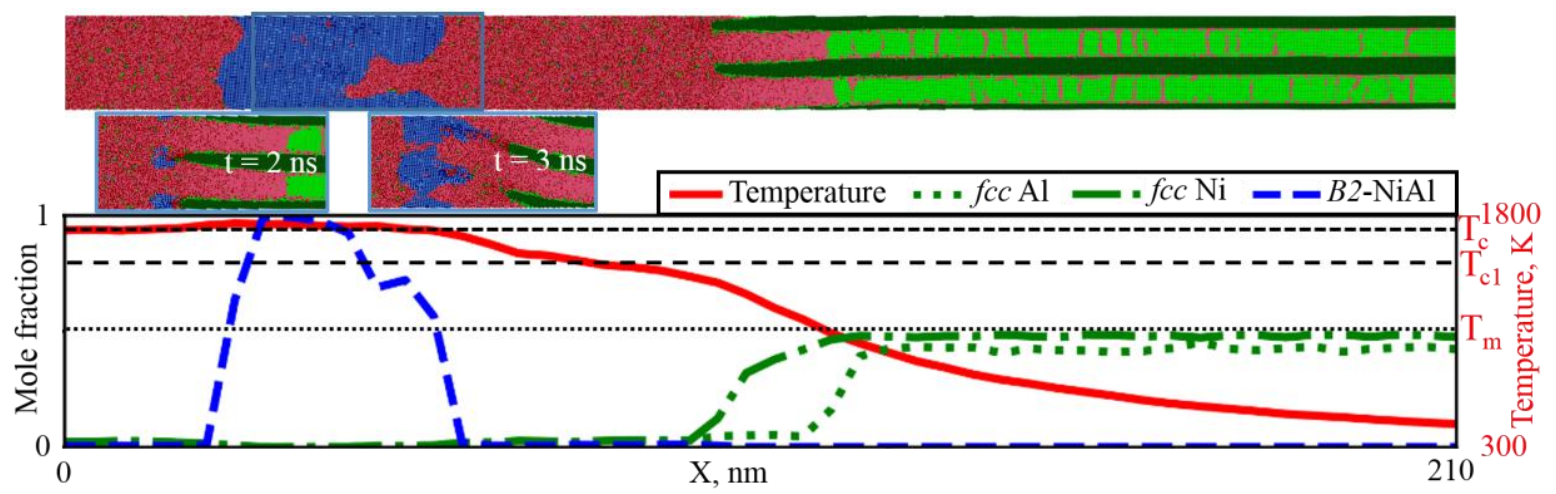

Fig. 16 Snapshot of the equiatomic system with $T_{0}=300 \mathrm{~K}$ at $t=6 \mathrm{~ns}$. Colors are: redliquid, blue-bcc and green-fcc. Dark atoms are Ni and light atoms are Al. The box corresponds to the insets. Profiles of temperature, fcc-Ni and fcc-Al mole fraction at the same time. The dashed lines refer to the melting temperature of $A l, T_{m}$, and the two temperatures of combustion corresponding to the two plateaus, $T_{c}$ and $T_{c 1}$.

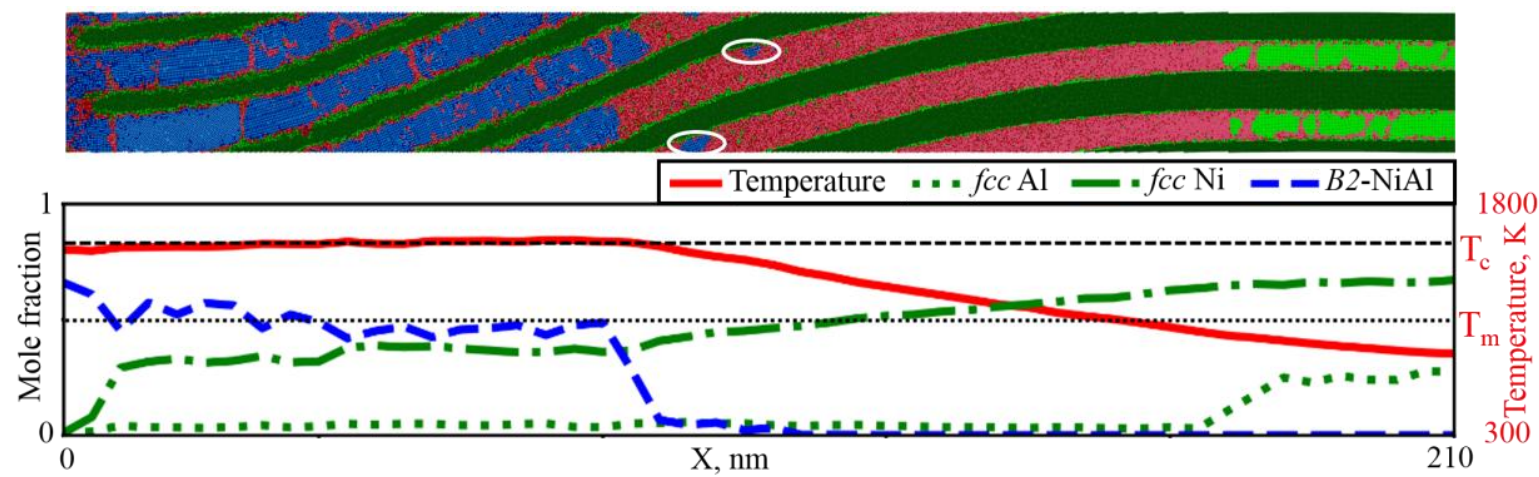

Fig. 17 Snapshot of the equiatomic system with $T_{0}=500 \mathrm{~K}$ at $t=10 \mathrm{~ns}$. Colors are: redliquid, blue-bcc and green-fcc. Dark atoms are Ni and light atoms are Al. Profiles of temperature, $f c c-N i$ and $f c c-A l$ mole fraction at the same time. The dashed lines refer to the melting temperature of $A l, T_{m}$, and the temperature of combustion, $T_{c}$.

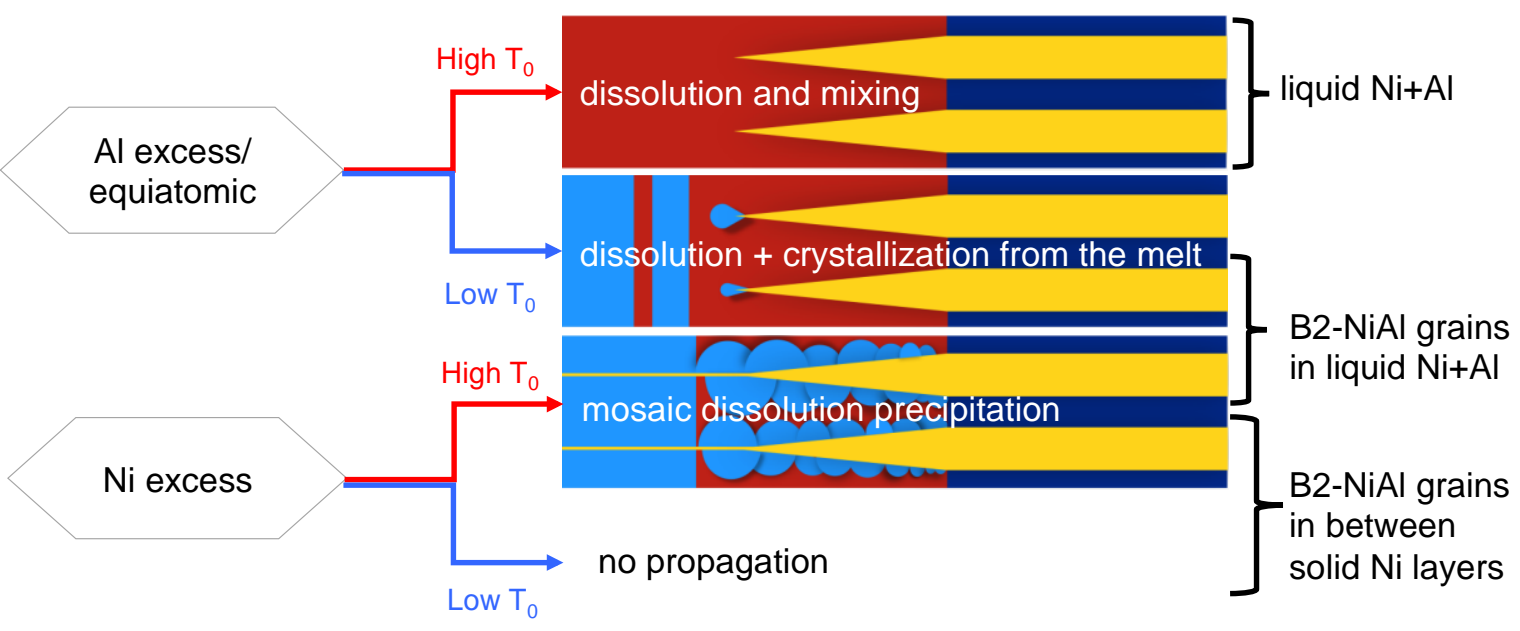

Fig. 18 Summary of the different regimes and final product microstructures according to stoichiometry and initial temperature. 
Direction of the reactive wave propagation

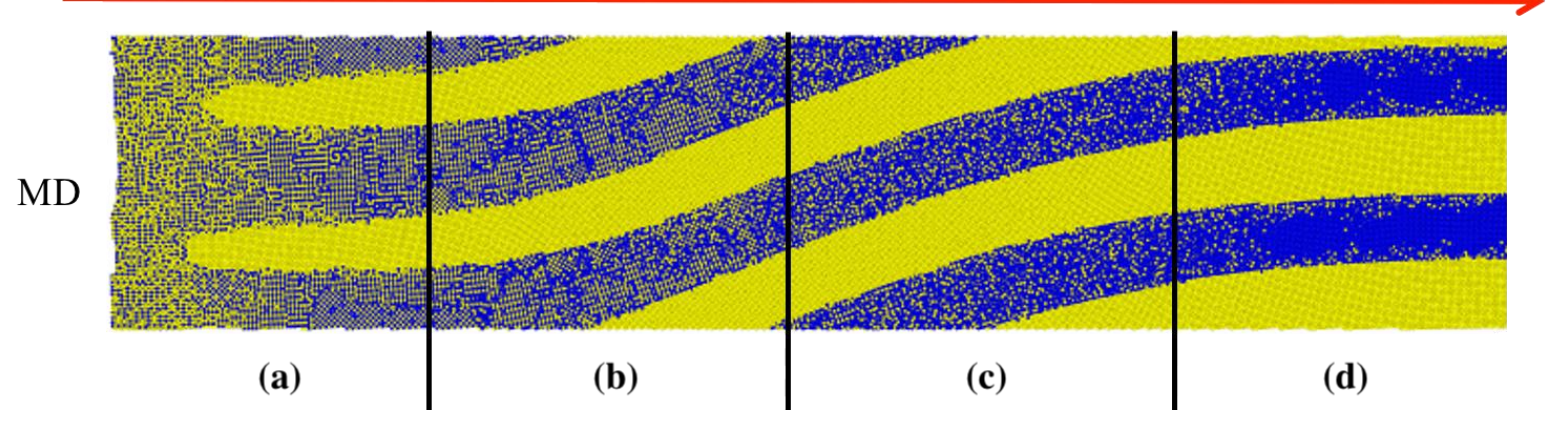

Fig. 19 Quenched reactive front according to $M D$. 
[1] A. S. Rogachev, Russ. Chem. Rev. 2008, 77, 21.

[2] T. W. Barbee and T. Weihs. Ignitable heterogeneous stratified structure for the propagating of an internal exothermic chemical reaction along an expanding wavefront and method of making same. U.S. Patent, (5538795), 1996.

[3] T.P. Weihs in Handbook of Thin Film Process Technology (Eds.: D. A. Glocker and S. I. Shah) IOP Publishing, Bristol, 1998.

[4 ] A. J. Gavens, D. Van Heerden, A. B. Mann, M. E. Reiss, and T. P. Weihs, J. Appl. Phys. 2000, 87, 1255.

[5] M. E. Reiss, C. M. Esber, D. Van Heerden, A. J. Gavens, M. E. Williams, and T. P. Weihs, Mater. Sci. Eng. A 1999, 261, 217.

[6] A. Duckham, S. J. Spey, J. Wang, M. E. Reiss, T. P. Weihs, E. Besnoin, and O. M. Knio, J. Appl. Phys. 2004, 96, 2336.

[7] S. Simões, F. Viana, M. Koçak, A. S. Ramos, M. T. Vieira, and M. F. Vieira, J. Mater. Eng. Perform. 2012, 21, 678.

[8] R. Grieseler, T. Welker, J. Muller, and P. Schaaf, Phys. Status Solidi 2012, 209, 512.

[9] B. Lehmert, J. Janczak-Rusch, G. Pigozzi, P. Zuraw, F. La Mattina, L. Wojarski, W. Tillmann, and L. P. H. Jeurgens, Mater. Trans. 2015, 56, 1015.

[10] J. Braeuer, J. Besser, M. Wiemer, and T. Gessner, Sens. Actuators A 2012, 188, 212.

[11] E. Ma, C. V. Thompson, L. A. Clevenger, and K. N. Tu, Appl. Phys. Lett. 1990, 57, 1262.

[12] E. Ma, Mater. Sci. Eng. A 2005, 398, 60.

[13] H. Sieber, J. S. Park, J. Weissmuller and J.H. Perepezko, Acta Mater. 2001, 49, 1139.

[14] A. K. Stover, N. M. Krywopusk, G. M. Fritz, S. C. Barron, J. D. Gibbins, T. P. Weihs , J. Mater. Sci. 2013, $48,5917$.

[15] R. J. Hebert and J. H. Perepezko, Scr. Mater. 2004, 50, 807.

[16] A. S. Rogachev, S. G. Vadchenko, and A. S. Mukasyan, Appl. Phys. Lett. 2012, 101, 063119.

[17] J. Kim, T. LaGrande, B. Reed, M. Taheri, M. Armstrong, W. King, N. Browning, G. Campbell, Science 2008, 321, 1472.

[18] G. Campbell, T. LaGrande, J. Kim, B. Reed, N. Browning, J. Electron Microsc. 2010, $59,567$.

[19] J. Kim, T. LaGrande, B. Reed, R. Knepper, T. Weihs, N. Browning, G. Campbell, Acta Mater. 2011, 59, 3571.

[20] R. Armstrong, Combust. Sci. Technol. 1990, 71,155.

[21] A. B. Mann, A. J. Gavens, M. E. Reiss, D. Van Heerden, G. Bao, and T. P. Weihs, J. Appl. Phys. 1997, 82, 1178.

[22] E. Ma, C. V. Thompson, and L. A. Clevenger, J. Appl. Phys. 1991, 69, 2211.

[23] E. Besnoin, S. Cerutti, O. M. Knio, and T. P. Weihs, J. Appl. Phys. 2002, 92, 5474. 
[24] M. Salloum and O. M. Knio, Combust. Flame 2010, 157, 288.

[25] L. Alawieh, T. P. Weihs, and O. M. Knio, Combust. Flame 2013, 160, 1857.

[26] Q. Jiang, H. Y. Tong, D. T. Hsu, K. Okuyama, and F. G. Shi, Thin Solid Films 1998, $312,357$.

[27] A. S. Shteinberg, V. A. Shcherbakov, and Z. A. Munir, Combust. Sci. Technol. 2001, $169,1$.

[28] A. Makino, Combust. Flame 2003, 134, 273.

[29] V. Turlo, O. Politano and F. Baras, Acta Mater. 2015, 99, 363.

[30] V. Turlo, O. Politano and F. Baras, Acta Mater. 2016, 120, 189.

[31] B. J. Alder and T. E. Wainwright, J. Chem. Phys. 1957, 27, 1208.

[32] S. Nosé, J. Chem. Phys. 1984, 81, 511.

[33] W. G. Hoover, Phys. Rev. A 1985, 31, 1695.

[34] W. G. Hoover, Phys. Rev. A 1986, 34, 2499.

[35] M. Parrinello and A. Rahman, Phys. Rev. Lett. 1980, 45, 1196.

[36] M. Parrinello and A. Rahman, J. Appl. Phys. 1981, 52, 7182.

[37] M. P. Allen and D. J. Tildesley. Computer Simulations of Liquids, Clarendon Press, Oxford, 1991.

[38] D. Frenkel and B. Smit. Understanding Molecular Simulation: From Algorithms to Applications. Academic Press, 2001.

[39] S. Plimpton, J. Comput. Phys. 1995, 117, 1.

[40] M. W. Finnis and J. E. Sinclair, Philos. Mag. A 1984, 50, 45.

[41] M. S. Daw and M. I. Baskes, Phys. Rev. B 1984, 29, 6443.

[42] A. F. Voter and S. P. Chen, in Characterization of Defects in Materials, MRS Online Proceedings Library Archive 1986, 82, 175.

[43] F. Ercolessi and J. B. Adams, Europhys. Lett. 1994, 26, 583.

[44] Y. Mishin, D. Farkas, M. J. Mehl, and D. A. Papaconstantopoulos, Phys. Rev. B 1999, 59, 3393.

[45] S. M. Foiles, M. I. Baskes, and M. S. Daw, Phys. Rev. B 1986, 33,7983.

[46] Y. Mishin, M. J. Mehl, D. A. Papaconstantopoulos, A. F. Voter, and J. D. Kress, Phys. Rev. B 2001, 63, 224106.

[47] M. I. Mendelev, S. Han, D. J. Srolovitz, G. J. Ackland, D. Y. Sun, and M. Asta, Philos. Mag. 2003, 83, 3977.

[48] F. Delogu, Nanotechnology 2007, 18, 065708.

[49] Y. Mishin, M. J. Mehl, and D. A. Papaconstantopoulos, Phys. Rev. B 2002, 65, 224114.

[50] S. M. Foiles and M. S. Daw, J. Mater. Research 1987, 2, 5

[51] M. Ludwig and P. Gumbsch, Model. Simul. Mater. Sci. Eng. 1995, 3, 533. 
[52] M. Asta, D. Morgan, J.J. Hoyt, B. Sadigh, J.D. Althoff and S.M.D.F de Fontaine, Phys. Rev. B. 1999, 59, 14271

[53] Y. Mishin, Acta Mater. 2004, 52, 1451

[54] G. P. Purja Pun and Y. Mishin, Philos. Mag. 2009, 89, 3245.

[55] V. Turlo, F. Baras and O. Politano, Model. Simul. Mater. Sci. Eng. 2017, 25, 064002.

[56] A. Stukowski, Model. Simul. Mater. Sci. Eng. 2010, 18, 015012.

[57] D. J Bacon, Yu. N Osetsky, R Stoller, and R. E Voskoboinikov, J. Nucl. Mater. 2003, $323,152$.

[58] J. D. Honeycutt and H. C. Andersen, J. Chem. Phys. 1987, 1, 4950.

[59] H. Jónsson and H. C. Andersen, Phys. Rev. Lett. 1988, 60, 2295.

[60] D. Faken and H. Jónsson, Comput. Mater. Sci. 1994, 2, 279.

[61] C. L. Kelchner, S. J. Plimpton, and J. C. Hamilton, Phys. Rev. B 1998, 58, 11085.

[62] G. J. Ackland and A. P. Jones, Phys. Rev. B 2006, 73, 054104.

[63] P. Geysermans, D. Gorse, and V. Pontikis, J. Chem. Phys. 2000, 113, 6382.

[64] V. Turlo, O. Politano, F. Baras, J. Appl. Phys. 2017, 121, 055304.

[65] C. Michaelsen, G. Lucadamo, and K. Barmak, J. Appl. Phys. 1996, 80, 6689.

[66] K. J. Blobaum, D. Van Heerden, A. J. Gavens, T.P. Weihs, Acta Mater. 2003, 51, 3871 .

[67] G. M. Fritz, S. J. Spey Jr., M. D. Grapes, and T. P. Weihs , J. Appl. Phys. 2013, 113, 014901

[68] G. M. Fritz, J.A. Grzyb, O. M. Knio, M. D. Grapes, and T. P. Weihs, , J. Appl. Phys. 2015, 118, 135101

[69] R. Knepper, M. R. Snyder, G. Fritz, K. Fisher, O. M. Knio, and T. P. Weihs, J. Appl. Phys. 2009, 105, 083504.

[70] M. A. Korchagin, T. F. Grigorieva, A. P. Barinova, and N. Z. Lyakhov, Int. J. SHS 2000, 9, 307.

[71] T. S. Dyer and Z. A. Munir, Metall. Mater. Trans. B 1995, 26, 603.

[72] A.P. Hard, P.V. Phung, Comb. and Flame 1973, 21, 77.

[73] A.G. Merzhanov and B.I. Khaikin, Prog. Energy Combust. Sci. 1988, $14,1$.

[74] A.S. Rogachev, S.G. Vadchenko , F. Baras , O. Politano, S. Rouvimov , N.V. Sachkova, M.D. Grapes, T.P. Weihs, A.S. Mukasyan, Combust. Flame 2016, 166, 158.

[75] P.J. McCluskey, J.J. Vlassak, J. Mater. Res. 2010, 25, 2086.

[76] P. Swaminathan, M.D. Grapes, K. Woll, S.C. Barron, D.A. LaVan, T.P. Weihs, J. Appl. Phys. 2013, 113, 143509

[77] M.D. Grapes, T. LaGrange, K. Woll, B.W. Reed, G.H. Campbell, D.A. Lavan, T.P. Weihs, APL Materials 2014, 2, 116102 
[78] J.C. Trenkle, L.J. Koerner, M.W. Tate, S.M. Gruner, T.P. Weihs, T.C. Hufnagel, Appl. Phys. Lett. 2008, 93, 081903.

[79] A.H. Kinsey, K. Slusarski, S. Sosa, T.P. Weihs, ACS Appl. Mater. Interfaces 2017, 9 22026.

[80] J.B. Xu, Y. Tai, C.B. Ru, J. Dai, Y.H. Ye, R.Q. Shen, P. Zhu, ACS Appl. Mater. Interfaces 2017, 9, 5580.

[81] K.L. Zhang, C. Rossi, M. Petrantoni, N. Mauran, J. Microelectromech. Syst. 2008, 17, 832.

[82] G. Taton, D. Lagrange, V. Conedera, L. Renaud, C. Rossi, J. Micromech. Microeng. 2013, 23, 105009.

[83] A.H. Kinsey, K. Slusarski, E. Krumheuer, T.P. Weihs, J. Mater. Sci. 2017, 52,11077.

[84] A.H. Kinsey, K. Slusarski, K. Woll, D. Gibbins, T.P. Weihs, J. Mater. Sci. 2016, 51, 5738 .

[85] J.D. Gibbins, A.K. Stover, N.M. Krywopusk, K. Woll, T.P. Weihs, Combust. Flame 2015, 162, 4408 .

[86] R.D. Murphy, R.V. Reeves, C.D. Yarrington, D.P. Adams, Appl. Phys. Lett. 2015, 107 234103.

[87] S. Sen, M. Lake, J. Wilden, P. Schaaf, Thin Solid Films 2017, 631, 99.

[88] S. Sen, M. Lake, R. Grieseler, P. Schaaf, Surf. Coat. Technol. 2017, 327, 25.

[89] O. Emadinia, S. Simoes, F. Viana, M.F. Vieira, A.J. Cavaleiro, A.S. Ramos, M.T. Vieira, Welding in the World 2016, 60, 337.

[90] L. Maj, J. Morgiel, M. Szlezynger, P. Bala, G. Cios, Mater. Chem. Phys. 2017, 193244

[91] L. Maj, J. Morgiel, Thin Solid Films 2017, 621, 165.

[92] A.I. Ustinov, S.A. Demchenkov, Intermetallics 2017, 84, 82.

[93] J.P.Liu, J. Kirchhoff, L. Zhou, M. Zhao, M.D. Grapes, D.S. Dale, M.D. Tate, H.T. Philipp, S.M. Gruner, T.P.Weihs, T.C. Hufnagel, J. Synchrotron Radiat. 2017, 24, 796.

[94] M.D. Grapes, T.P. Weihs, Combust. Flame 2016, 172, 105.

[95] K.R. Overdeep, T.P. Weihs, J. Therm. Anal. Calorim. 2015, 122, 787.

[96] K.V. Manukyan, W.P. Tan, R.J. deBoer, E.J. Stech, A. Aprahamian, M. Wiescher, S. Rouvimov, K.R. Overdeep, C.E. Shuck, T.P. Weihs, A.S. Mukasyan, ACS Appl. Mater. Interfaces 2015, 7, 11272.

[97] Indium Corporation: http://www.indium.com/nanofoil/.

[98] Zhongmin Long, Bo Dai, Shijie Tan, Yong Wang, Xianhua Wei, Ceram. Int. 2017, 43 17000 .

[99] A. S. Rogachev, S. G. Vadchenko, A. A. Nepapushev, A. S. Mukasyan, Int. J. SHS 2016, 25, 234.

[100] S. Simoes, E. Viana, A.S. Ramos, M.T. Vieira, M.F. Vieira, Mat. Chem. Phys. 2016, $171,73$. 
[101] S. Kanetsuki, S. Miyake, K. Kuwahara, T. Namazu, Japan. J. Appl. Phys. 2016, 55, $06 \mathrm{GP} 17$.

[102] J. Braeuer, J. Besser, E. Tomoscheit, D. Klimm, S. Anbumani, M. Wiemer, and T. Gessner, ECS Trans. 2013, 50, 241.

[103] J. Braeuer, J. Besser, M. Wiemer, and T. Gessner, Sens. Actuators A 2012, 188, 212.

[104] R.J. Hooper, D.P. Adams, D. Hirschfeld, M.V. Manuel, J. Electron. Mater. 2016, 45, 1.

[105] S.C. Kelly, N.N. Thadhani, J. Appl. Phys. 2016, 119, 095903.

[106] Y. Gurler and S. Ozgen, Mater. Lett. 2003, 57, 4336.

[107] N. S. Weingarten, W.D. Mattson, and B.M. Rice, J. Appl. Phys. 2009, 106, 063524.

[108] W. Zhang, Y. Peng, and Z. Liu, AIP Advances 2014, 4, 057110.

[109] H. Yang, Y. Lu, M. Chen, and Z. Guo, Sci. China Ser. G 2007, 50,407.

[110] Y. Mishin, A. Y. Lozovoi, and A. Alavi, Phys. Rev. B 2003, 67, 014201.

[111] B. Soule De Bas and D. Farkas, Acta Mater. 2003, 51, 1437.

[112] A. Kerrache, J. Horbach, and K. Binder, EPL 2008, 81, 58001.

[113] E. V. Levchenko, A. V. Evteev, I. V. Belova, and G. E. Murch, Acta Mater. 2011, 59, 6412.

[114] A. Ovrutsky and A. Prokhoda, Comput. Mater. Sci. 2013, 79,193.

[115] P. Kuhn and J. Horbach, Phys. Rev. B 2013, 87, 014105.

[116] X. Q. Zheng, Y. Yang, Y. F. Gao, J. J. Hoyt, M. Asta, and D. Y. Sun, Phys. Rev. E 2012, 85, 041601.

[117] A.S. Rogachev, S.G. Vadchenko, F. Baras, O. Politano, S. Rouvimov , N.V. Sachkova, A.S. Mukasyan, Acta Mater. 2014, 66, 86.

[118] O. Politano and F. Baras, J. Alloys Compd. 2015, 652, 25.

[119] V. Turlo, O. Politano, F. Baras, J. Alloys Compd. 2017, 708, 989.

[120] F. Delogu, Nanotechnology 2007, 18, 065708.

[121] P. Song and D. Wen, J. Phys. Chem. C 2010, 114, 8688.

[122] D. S. Sundaram, P. Puri, and V. Yang, J. Phys. Chem. C 2013, 117, 7858.

[123] A. V. Evteev, E. V. Levchenko, D. P. Riley, I. V. Belova, and G. E. Murch, Philos. Mag. Lett. 2009, 89, 815.

[124] D. S. Sundaram, V. Yang, and V. E. Zarko, Combust. Explosion Shock Waves 2015, 51, 173.

[125] D. S. Sundaram, P. Puri, and V. Yang, J. Nanopart. Res. 2014 16, 1.

[126] A. V. Evteev, E. V. Levchenko, F. A. Hagel, I. V. Belova, and G. E. Murch, Intermetallics 2011, 19, 934.

[127] E. V. Levchenko, A. V. Evteev, D. P. Riley, I. V. Belova, and G. E. Murch, Comput. Mater. Sci. 2010, 47, 712. 
[128] B. J. Henz, T. Hawa, and M. Zachariah, J. Appl. Phys. 2009, 105, 124310.

[129] B. J. Henz, T. Hawa, and M. Zachariah, Mol. Simul. 2009, 35, 804.

[130] M. J. Cherukara, T. P. Weihs, and A. Strachan, Acta Mater. 2015, 96, 1.

[131] E. V. Levchenko, A. V. Evteev, R. Kozubski, I. V. Belova, and G. E. Murch, Phys. Chem. Chem. Phys. 2011, 13, 1214.

[132] A. V. Evteev, E. V. Levchenko, I. V. Belova, and G. E. Murch, Intermetallics 2011, 19, 848-854.

[133] A. V. Evteev, E. V. Levchenko, I. V. Belova, and G. E. Murch, Phys. Metals Metallogr. 2012, 113.

[134] S.-G. Lee, S.-P. Kim, K.-R. Lee, and Y.-C. Chung, J. Magn. Magn. Mater. 2005, 286, 394.

[135] S.-G. Lee and Y.-C. Chung, J. Appl. Phys. 2006, 100, 074905.

[136] S.-G. Lee and Y.-C. Chung, Jpn. J. Appl. Phys. 2006, 45, 99.

[137] S.-G. Lee and Y.-C. Chung, Appl. Surf. Sci. 2007, 253, 8896.

[138] A. Hassani, A. Makan, K. Sbiaai, A. Tabyaoui, and A. Hasnaoui, Appl. Surf. Sci. 2015, 349,785 .

[139] S. Zhao, T. C. Germann, and A. Strachan, Phys. Rev. B 2007, 76, 014103.

[140] F. Baras, O. Politano, Phys. Rev. B 2011, 84, 024113.

[141] M. J. Cherukara, K. G. Vishnu, and A. Strachan, Phys. Rev. B 2012, 86, 075470.

[142] S. Izvekov and B. M. Rice, J. Chem. Phys. 2012, 137, 094704.

[143] J. C. Crone, J. Knap, P. W. Chung, and B. M. Rice, Appl. Phys. Lett. 2011, 98, 141910.

[144] N. S. Weingarten, W. D. Mattson, A. D. Yau, T. P. Weihs, and B. M. Rice, J. Appl. Phys. 2010, 107, 093517.

[145] N. S. Weingarten and B. M. Rice, J. Phys.: Condens. Matter. 2011, 23, 275701.

[146] F. Rizzi, M. Salloum, Y. Marzouk, R. Xu, M. Falk, T. Weihs, G. Fritz, and O. Knio, Multiscale Model. Simul. 2011, 9, 486.

[147] R.-G. Xu, M. L. Falk, and T. P. Weihs, J. Appl. Phys. 2013, 114, 163511.

[148] O. Politano, F. Baras, A.S. Mukasyan, S.G. Vadchenko, A.S. Rogachev, Surf. Coat. Technol. 2013, 215, 485.

[149] F. Baras and O. Politano, Acta. Mater. 2018, 148, 133

[150] F. Baras, J. Alloys Compd. 2008, 455, 113.

[151] A. Rogachev, A. Grigoryan, E. Illarionova, I. Kanel, A. Merzhanov, A. Nosyrev, N. Sachkova, V. Khvesyuk, P. Tsygankov, Combust. Explosion Shock Waves 2004, 40, 166.

[152] L. A. Clevenger, C. V. Thompson, K. N. Tu, J. Appl. Phys. 1990, 67, 2894.

[153] D. P. Adams, M. A. Rodriguez, C. P. Tigges, P. G. Kotula, J. Mater. Res. 2006, 21, 3168. 
[154] S. C. Barron, S. T. Kelly, J. Kirchhoff, R. Knepper, K. Fisher, K. J. T. Livi, E. M. Dufresne, K. Fezzaa, T. W. Barbee, T. C. Hufnagel, T. P. Weihs, J. Appl. Phys. 2013, $114,223517$.

[155] D. P. Adams, M. A. Rodriguez, J. P. McDonald, M. M. Bai, J. E. Jones, L.Brewer, J. J. Moore, J. Appl. Phys. 2009, 106, 093505.

[156] P. Zhu, J. C. M. Li and C. T. Liu, Mater. Sci. Eng., A 2003, 357, 248257. 